Article

\title{
Derivation of Daily Evaporative Fraction Based on Temporal Variations in Surface Temperature, Air Temperature, and Net Radiation
}

\author{
Jing Lu ${ }^{1,2}$, Ronglin Tang ${ }^{1}$, Huajun Tang ${ }^{3, *}$ and Zhao-Liang $\mathrm{Li}^{3,4}$ \\ 1 State Key Laboratory of Resources and Environmental Information System, Institute of Geographic \\ Sciences and Natural Resources Research, Chinese Academy of Sciences, Beijing 100101, China; \\ E-Mails: lujingljx@126.com (J.L.); trl_wd@163.com (R.T.) \\ 2 University of Chinese Academy of Sciences, Beijing 100049, China \\ 3 Key Laboratory of Agri-informatics, Ministry of Agriculture/Institute of Agricultural Resources and \\ Regional Planning, Chinese Academy of Agricultural Sciences, Beijing 100081, China \\ 4 ICube, UdS, CNRS, Bld Sebastien Brant, BP10413, Illkirch 67412, France; E-Mail: lizl@unistra.fr \\ * Author to whom correspondence should be addressed; E-Mail: hjtang@caas.cn;
} Tel.: +86-10-8210-9395;

Received: 30 August 2013; in revised form: 25 September 2013 / Accepted: 9 October 2013 / Published: 22 October 2013

\begin{abstract}
Based on surface energy balance and the assumption of fairly invariant evaporative fraction (EF) during daytime, this study proposes a new parameterization scheme of directly estimating daily EF. Daily EF is parameterized as a function of temporal variations in surface temperature, air temperature, and net radiation. The proposed EF parameterization scheme can well reproduce daily EF estimates from a soil-vegetation-atmosphere transfer (SVAT) model with a root mean square error (RMSE) of 0.13 and a coefficient of determination $\left(R^{2}\right)$ of 0.719 . When input variables from in situ measurements at the Yucheng station in North China are used, daily EF estimated by the proposed method is in good agreement with measurements from the eddy covariance system corrected by the residual energy method with an $R^{2}$ of 0.857 and an RMSE of 0.119. MODIS/Aqua remotely sensed data were also applied to estimate daily EF. Though there are some inconsistencies between the remotely sensed daily EF estimates and in situ measurements due to errors in input variables and measurements, the result from the proposed parameterization scheme shows a slight improvement to SEBS-estimated EF with remotely sensed instantaneous inputs.
\end{abstract}


Keywords: evaporative fraction; temporal variation; remote sensing; SVAT model

\section{Introduction}

Estimation of evapotranspiration (ET) using remotely sensed data has been a significant topic because of the capability of remote sensing to quickly obtain surface information at large spatial scales with less cost [1-6]. Current models for ET estimation from remotely sensed data, e.g., the surface energy balance system (SEBS), the surface energy balance algorithm for land (SEBAL), and two-source models, depend primarily on observations at the satellite overpass time [7-10]. Because of the influences of atmosphere, observational angular, heterogeneous surfaces, and scale issues, there are some uncertainties in retrieved surface variables from remote sensing [11-13]. Therefore, the accuracy of ET estimates could be largely subjected to retrieval errors in remotely sensed surface variables [14-16].

Evaporative fraction (EF) is an important index for partitioning surface available energy $(Q)$. A number of studies based on in situ measurements as well as analyses from land process modeling showed that EF exhibits a typical concave-up shape and is relatively stable during daytime [17-21]. Therefore, the constant EF method is often used to estimate daily ET from remotely sensed data, which converts the instantaneous ET at the satellite overpass time to daily values under the assumption of self-preservation of EF in a diurnal cycle [22-25]. EF at the instantaneous scale can be calculated by latent heat flux $(L E)$ and $Q$ from remotely sensed data. Some methods of estimating EF directly from remote sensing have been developed, in which the feature space method is one of the representative parameterizations [26,27]. Directly parameterizing EF can obviate uncertainties caused by the calculation of various resistances [28]. Because the temporal variation of surface variables is less sensitive to the retrieval errors [29,30], the day-night surface temperature difference from MODIS global daily products and the change rate of surface temperature during the morning from MSG-SEVIRI data and FY-2C data were used to construct the triangle feature space to improve EF estimation [31-33]. However, determination of the dry and wet edges in triangle feature space depends on the domain size and the spatial resolution of remotely sensed images [34,35], which could result in more uncertainties.

The major objective of this study is to develop a new parameterization scheme for directly determining daily EF from temporal variations in surface variables. The proposed method will resolve uncertainties in EF estimation caused by errors in remotely sensed variables. Using simulation from an atmosphere-land exchange (ALEX) model [36], a new EF parameterization scheme is proposed in Section 2. The inputs from in situ measurements at the Yucheng station in North China and the MODIS products are also used to analyze performance of the proposed EF method. Data are described in Section 3. Results will be discussed in Section 4. To further demonstrate that the EF estimate from temporal variation is less sensitive to the retrieval error of remotely sensed data, daily EF estimates from remotely sensed data are also compared with the result from the SEBS model with instantaneous inputs. Finally, some conclusions are given in Section 5. 


\section{Method}

\subsection{Background of Theory}

\subsubsection{Radiometric Heat Conductance $P_{\mathrm{rad}}$}

According to the boundary similarity theory, it is the aerodynamic temperature $\left(T_{\text {aero }}\right)$ which determines the loss of sensible heat flux $(H)$ from a surface [37]. $T_{\text {aero }}$ is defined as the extrapolation of the air temperature profile down to an effective height within the canopy at which the vegetation components of heat fluxes arise [38,39], but it is not an easily measured variable in reality. For $H$ estimates, $T_{\text {aero }}$ is often replaced by surface radiative temperatures $\left(T_{\mathrm{s}}\right)$ by adding supplementary resistance, defining a radiometric exchange coefficient, or constructing the relationship between $T_{\text {aero }}$ and $T_{\mathrm{s}}[39-41]$. In this study, $H$ is expressed by

$$
H=P_{\text {rad }}\left(T_{s}-T_{\mathrm{a}}\right)
$$

where $T_{\mathrm{a}}$ is the air temperature $(\mathrm{K}) ; P_{\text {rad }}$ is defined as radiometric heat conductance corresponding to $T_{\mathrm{s}}$ or the heat transfer efficiency $\left(\mathrm{W} /\left(\mathrm{m}^{2} \cdot \mathrm{K}\right)\right)$. Figure 1 shows relationships among the values of $P_{\text {rad }}$ for different atmospheric conditions. Data are from the simulation by ALEX. Atmosphere forcing data and details about ALEX-based simulations can be found in Appendix. The majority of $P_{\text {rad }}$ vary from $0-100 \mathrm{~W} /\left(\mathrm{m}^{2} \cdot \mathrm{K}\right)$. When the wind speed is the same, the root mean square error (RMSE) caused by the variations of atmosphere conditions is $\sim 9 \mathrm{~W} /\left(\mathrm{m}^{2} \cdot \mathrm{K}\right)$, and the coefficient of determination $\left(R^{2}\right)$ is $\sim 0.9$. This result indicates that the variation of atmospheric conditions could not lead to serious error in $P_{\text {rad }}$ estimates.

Figure 1. Relationships among the values of $P_{\mathrm{rad}}$ for different atmospheres under clear days but for the same wind speed observations from the measurements at the Yucheng station on 24 April 2010 (Data are from the simulation by ALEX under different vegetation cover and soil water content conditions for each atmosphere, and atmosphere forcing on three representative days was measured at the Yucheng station on 24 April (DOY 114), 29 May (DOY 149), and 21 July (DOY 202) 2010, which can be found in Appendix. $P_{\text {rad }}$ is calculated by simulated $H$ and $T_{\mathrm{s}}-T_{\mathrm{a}}$.)

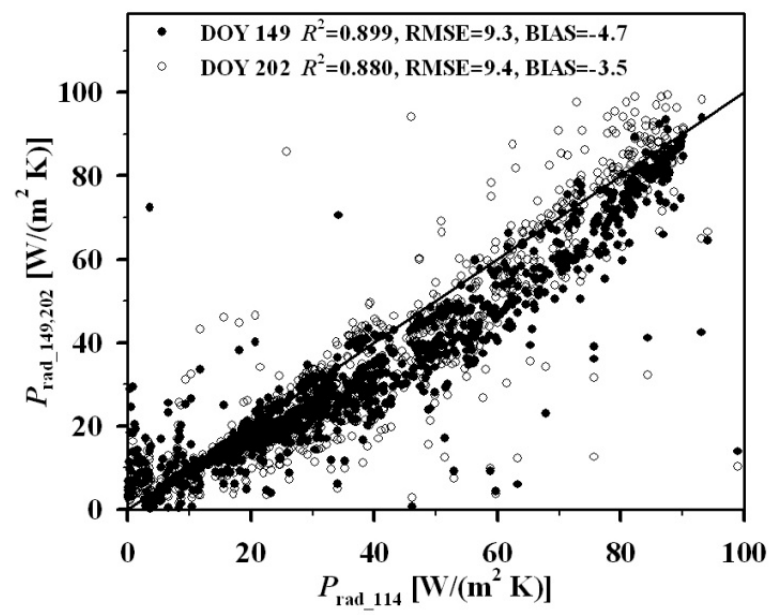


Figure 2a shows the variation of $P_{\text {rad }}$ in a diurnal cycle for the same atmospheric condition but with different wind speed. Because wind speed is the major driving force for heat transfer, the magnitude of $P_{\text {rad }}$ is determined primarily by wind speed. For the same surface condition, high wind speed results in a large value in $P_{\text {rad }}$. It is evident that given a certain wind speed, $P_{\text {rad }}$ mainly increases with increasing $f_{\mathrm{c}}$ (see Figure $2 \mathrm{~b}$ ). This is because the roughness length for heat transfer at the vegetated surface is generally larger than that at the bare soil surface [37]. As a result, $P_{\text {rad }}$ is higher at the surface with dense vegetation cover than the bare soil surface. The conclusion of the dependence of $P_{\text {rad }}$ on wind speed and $f_{\mathrm{c}}$ is similar to the studies from Carlson et al. and Lagouarde et al. [42,43]. They concluded that the heat conductance is highly sensitive to wind speed, roughness, and vegetation amount.

Figure 2. Variation of $P_{\text {rad }}$ in a diurnal cycle (a) for the same atmosphere and surface conditions but with various wind speeds (Atmosphere forcing data, including air temperature, water vapor pressure, incoming solar radiation, etc., are from the measurements at the Yucheng station on 24 April 2010 (DOY 114). Fractional vegetation cover $\left(f_{\mathrm{c}}\right)$ is 0.5 , and soil water content (SWC) is $0.21 \mathrm{~m}^{3} / \mathrm{m}^{3}$. WH denotes the high wind speed condition, which is from the measurement at the Yucheng station on 24 April 2010, and the maximum wind speed during the day is $6.1 \mathrm{~m} / \mathrm{s}$; WM represents the medium wind speed condition from the measurement on 29 May 2010 (DOY 149), and the maximum wind speed is $3.6 \mathrm{~m} / \mathrm{s}$; WL denotes the low wind speed condition measured on 21 July 2010 (DOY 202), and the maximum wind speed is $1.3 \mathrm{~m} / \mathrm{s}$ ) and (b) for the same atmosphere and wind speed but with different fractional vegetation cover (atmosphere and wind speed are from the measurements at the Yucheng station on 24 April 2010).
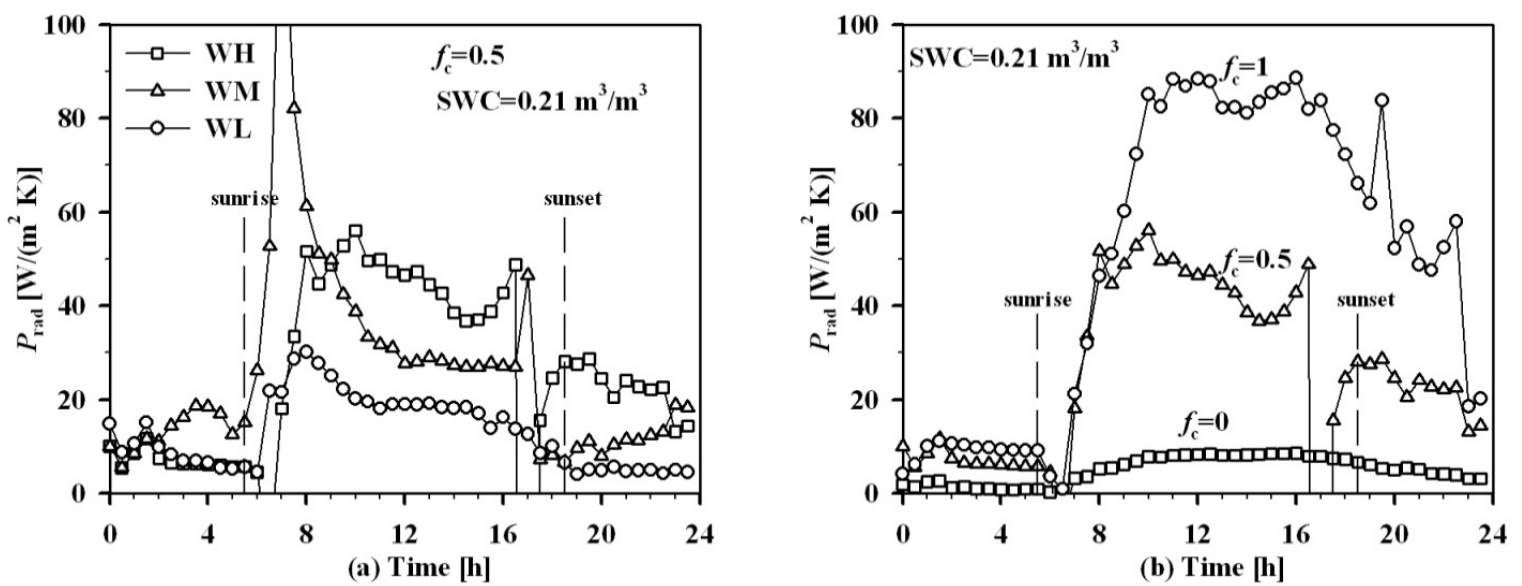

Referencing the study of Carlson et al. [44], it can be inferred from Figure 3 that $P_{\text {rad }}$ approximately linearly varies with $f_{\mathrm{c}}$ when wind speed is given. The variation in $P_{\mathrm{rad}}$ along the vertical axis is caused by soil water content (SWC). For the same atmospheric condition, the RMSE in $P_{\text {rad }}$ caused by the approximation of linear function of $f_{\mathrm{c}}$ is $\sim 5 \mathrm{~W} /\left(\mathrm{m}^{2} \cdot \mathrm{K}\right)$, i.e., the variation in $P_{\text {rad }}$ due to soil water content is $\sim 5 \mathrm{~W} /\left(\mathrm{m}^{2} \cdot \mathrm{K}\right)$. Although soil water content is certainly a critical variable that controls the partitioning of surface available energy into $H$ and $L E$, the role of SWC on $P_{\text {rad }}$ is not significant. This is because radiative $T_{s}$ can reflect surface soil moisture to a certain degree [39]. 
Figure 3. Relationship between $P_{\text {rad }}$ and $f_{\mathrm{c}}$ for three atmosphere conditions at the Yucheng station on 24 April (DOY 114), 29 May (DOY 149) and 21 July (DOY 202) 2010 ( $P_{\text {rad }} \mathrm{S}$ calculated by simulated $H$ and $T_{\mathrm{s}}-T_{\mathrm{a}}$ at 10:30 A.M.)

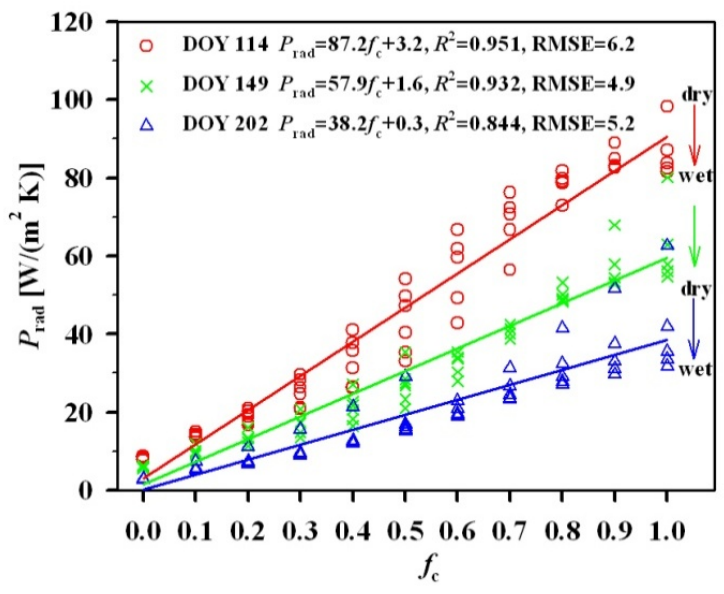

\subsubsection{Diurnal Cycle of EF}

EF is generally defined as the ratio of $L E$ to $Q$. Therefore, EF at any time $t$ in a day can be expressed by

$$
E F(t)=\frac{L E(t)}{R_{\mathrm{n}}(t)-G(t)}
$$

where $R_{\mathrm{n}}$ is the net radiation $\left(\mathrm{W} / \mathrm{m}^{2}\right)$; $G$ is the soil heat flux $\left(\mathrm{W} / \mathrm{m}^{2}\right) ; R_{\mathrm{n}}-G$ is the surface available energy, i.e., $Q$. A large number of studies indicated that $\mathrm{EF}$ during daytime about from 9:00 to 15:00 is relatively stable $[17,24,45]$. The cases for different surface and atmospheric conditions shown in Figure 4 also demonstrate this conclusion. Atmospheric status is generally more stable in the morning than in the afternoon. Therefore, EF during the morning from about 9:00 to 12:00 is relatively steadier than those values during the afternoon. In this study, daily average EF, daytime average EF, and morning average EF are calculated by the following Equations (3-5), respectively.

$$
\begin{gathered}
E F_{\text {daily }}=\frac{\overline{L E_{\text {daily }}}}{\overline{R_{\text {n_daily }}}} \\
E F_{\text {daytime }}=\frac{\overline{L E_{9: 00-15: 00}}}{\overline{R_{\mathrm{n} \_9: 00-15: 00}-G_{9: 00-15: 00}}} \\
E F_{\text {morning }}=\frac{\overline{L E_{9: 00-12: 00}}}{\overline{R_{\mathrm{n} \_9: 00-12: 00}-G_{9: 00-12: 00}}}
\end{gathered}
$$

From ALEX-simulated data driven by the atmospheric forcing at the Yucheng station in 2010 (details about data can be found in Appendix), the conclusion that daily average EF can be related to daytime average EF and morning average EF for the majority of cases can be justified (see red and green symbols in Figure 5a). Some dispersed data mainly occur under the atmospheric condition on 26 
March 2010 (DOY 85). This may be related to relatively low air humidity on this day (see Figure A1a in Appendix). Under the low humidity condition, the assumption of self-preservation EF may not be valid, e.g., Gentine et al. concluded that the self-preservation of daytime EF is mainly constrained to high humidity and solar radiation [19]. The daily average EF from in situ measurements at the Yucheng station during the wheat growth period in 2012 (details about data can be found in Section 3.2) is generally greater than the EF during daytime (see Figure 5b). Because of the relatively invariant $\mathrm{EF}$ during daytime, daily average $\mathrm{EF}$ is further related to an instantaneous EF at 10:30 A.M. (see blue triangles in Figure 5), and the RMSE is within 0.2. Therefore, daily average EF can be estimated by an instantaneous EF during daytime or during the morning to a certain degree, especially under the conditions of clear skies, humid air, and strong solar radiation.

Figure 4. Diurnal cycle of EF driven by atmospheric forcing obtained at the Yucheng station (a) on 24 April (DOY114), and (b) on 21 July (DOY 202) 2010 (The horizontal lines with different color correspond to daily average EF for each case).
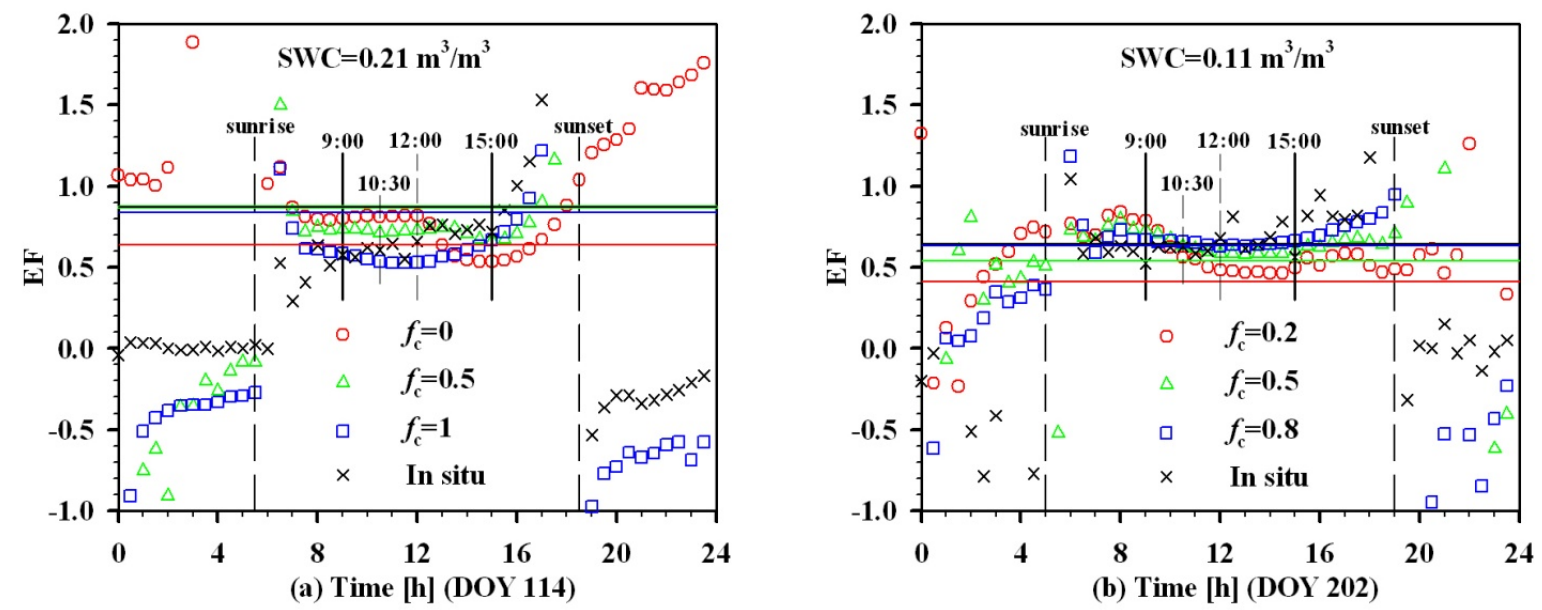

Figure 5. Relationships between daily average $\mathrm{EF}$ and $\mathrm{EF}$ at different times in one day for (a) ALEX-simulated data driven by the atmospheric forcing at the Yucheng station in 2010, and (b) in situ measurements at the Yucheng station during the wheat growth period in 2012.

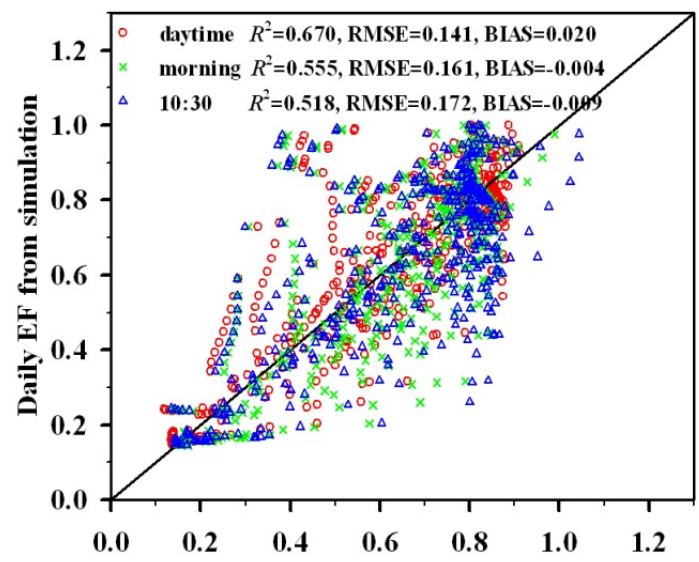

(a) EF from simulation at different times

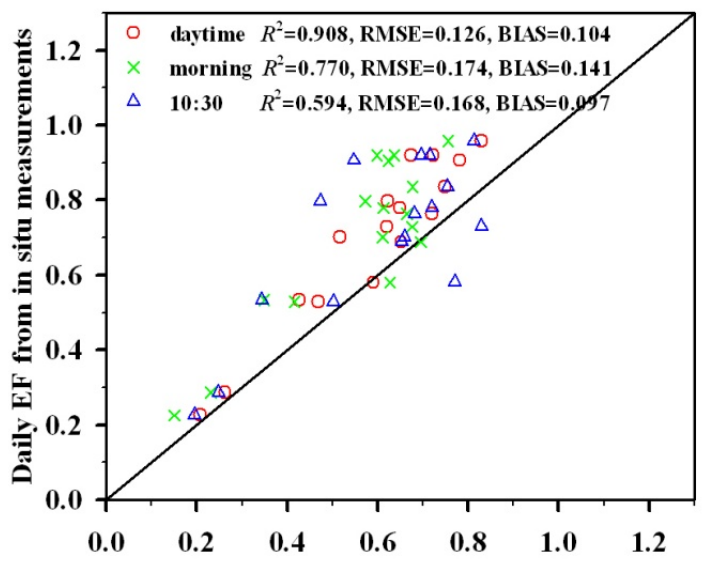

(b) EF from in situ measurements at different times 


\subsection{Parameterization for EF Based on SVAT Modeling}

The surface energy balance equation at any time $t$ in a day can be written as

$$
L E(t)=R_{\mathrm{n}}(t)-G(t)-H(t)=Q(t)-H(t)
$$

The derivative of Equation (6) with respect to $t$ can be written as,

$$
\frac{d L E}{d t}=\frac{d Q}{d t}-\frac{d H}{d t}
$$

Combining with Equation (1), if atmosphere and surface properties do not change greatly during a short study period of $d t$, the following equation can be derived:

$$
\frac{d L E}{d t} / \frac{d Q}{d t}=1-\frac{d H}{d t} / \frac{d Q}{d t}=1-P_{\text {rad }}\left(\frac{d T_{s}}{d t}-\frac{d T_{\mathrm{a}}}{d t}\right) / \frac{d Q}{d t}
$$

$Q$ is the difference of $R_{\mathrm{n}}$ and $G$. $G$ is frequently parameterized as a function of the vegetation index and $R_{\mathrm{n}}[9,46]$, i.e.,

$$
G=R_{\mathrm{n}}\left(f_{\mathrm{c}} \Gamma_{\mathrm{c}}+\left(1-f_{\mathrm{c}}\right) \Gamma_{\mathrm{s}}\right)
$$

where $\Gamma_{\mathrm{c}}$ and $\Gamma_{\mathrm{s}}$ are the ratio of $G$ to $R_{\mathrm{n}}$ for full vegetation cover and bare soil, respectively. Values of $\Gamma_{\mathrm{c}}$ generally range between 0.05 and 0.1 , and $\Gamma_{\mathrm{s}}$ varies from 0.2 to 0.5 [47]. From Equation (9), it can be obtained that $Q=R_{\mathrm{n}}\left(1-\left(f_{\mathrm{c}} \Gamma_{\mathrm{c}}+\left(1-f_{\mathrm{c}}\right) \Gamma_{\mathrm{s}}\right)\right)$. Therefore, $d Q / d t$ in Equation (8) can be replaced by the variation of net radiation $\left(d R_{\mathrm{n}} / d t\right)$ with a linear function of $f_{\mathrm{c}}$, and $1 /(d Q / d t)$ in Equation $(8)$ can be then approximated by $\left(a f_{\mathrm{c}}+b\right) /\left(d R_{\mathrm{n}} / d t\right)$. As analyzed in Section 2.1.1, $P_{\text {rad }}$ mainly changes with the wind speed and $f_{\mathrm{c}}$, and can be assumed as a linear function of $f_{\mathrm{c}}$ given a wind speed, i.e., $P_{\mathrm{rad}}=c f_{\mathrm{c}}+d$. As a result, Equation (8) becomes

$$
\frac{d L E}{d t} / \frac{d Q}{d t}=1-\left(A \times f_{\mathrm{c}}^{2}+B \times f_{\mathrm{c}}+C\right)\left(\frac{d T_{s}}{d t}-\frac{d T_{\mathrm{a}}}{d t}\right) / \frac{d R_{\mathrm{n}}}{d t}
$$

where $A, B$, and $C$ are coefficients depending primarily on atmospheric conditions. Because EF is relatively invariant during daytime $(d E F / d t \approx 0)$, especially during the morning time, Equation (10) can be approximated as EF at time $t$ during the morning, i.e.,

$$
\frac{d L E}{d t} / \frac{d Q}{d t}=\frac{L E(t)}{Q(t)}=E F(t)=1-\left(A \times f_{\mathrm{c}}^{2}+B \times f_{\mathrm{c}}+C\right)\left(\frac{d T_{s}}{d t}-\frac{d T_{\mathrm{a}}}{d t}\right) / \frac{d R_{\mathrm{n}}}{d t}
$$

$T_{\mathrm{s}}, T_{\mathrm{a}}$, and $R_{\mathrm{n}}$ on cloud-free days generally vary linearly with time during the morning about from $1.5 \mathrm{~h}$ to $4.5 \mathrm{~h}$ after sunrise [29,32] (see bold red, green, and blue lines in Figure 6), so their change rates with time during the morning can be used in Equation (11). In addition, daily average EF can be approximated by morning EF or an instantaneous EF during the morning as illustrated in Section 2.1.2. Therefore, the following equation is derived,

$$
E F_{\text {daily }} \approx E F_{\text {morning }} \approx E F(t)=1-\left(A \times f_{\mathrm{c}}^{2}+B \times f_{\mathrm{c}}+C\right) \frac{T_{s}^{\prime}(t)-T_{\mathrm{a}}{ }^{\prime}(t)}{R_{\mathrm{n}}{ }^{\prime}(t)}
$$

where $T_{\mathrm{s}}{ }^{\prime}(t), T_{\mathrm{a}}{ }^{\prime}(t)$, and $R_{\mathrm{n}}{ }^{\prime}(t)$ are change rates of $T_{\mathrm{s}}, T_{\mathrm{a}}$, and $R_{\mathrm{n}}$ during the morning about from $1.5 \mathrm{~h}$ to $4.5 \mathrm{~h}$ after sunrise, i.e., the slopes of linear relationships or the derivative of linear functions. 
Figure 6. Variations of (a) $T_{\mathrm{s}}$ and $T_{\mathrm{a}}$, and (b) $R_{\mathrm{n}}$ during a diurnal cycle for an ALEX-simulated case given fractional vegetation cover $\left(f_{\mathrm{c}}\right)$ of 0.5 and soil water content (SWC) of $0.21 \mathrm{~m}^{3} / \mathrm{m}^{3}$ and the atmospheric forcing at the Yucheng station on 24 April (DOY 114) 2010. The bold red, green, and blue lines denote the approximately linear variations of $T_{\mathrm{s}}$, $T_{\mathrm{a}}$, and $R_{\mathrm{n}}$ during the morning about from $1.5 \mathrm{~h}-4.5 \mathrm{~h}$ after sunrise. delt $T_{\mathrm{s}}$, delt $T_{\mathrm{a}}$, and delt $R_{\mathrm{n}}$ are the differences of $T_{\mathrm{s}}, T_{\mathrm{a}}$, and $R_{\mathrm{n}}$ between 1:30 P.M. and 1:30 A.M., respectively. The sunrise is 5:30 A.M., and the sunset is 6:30 P.M. on 24 April.
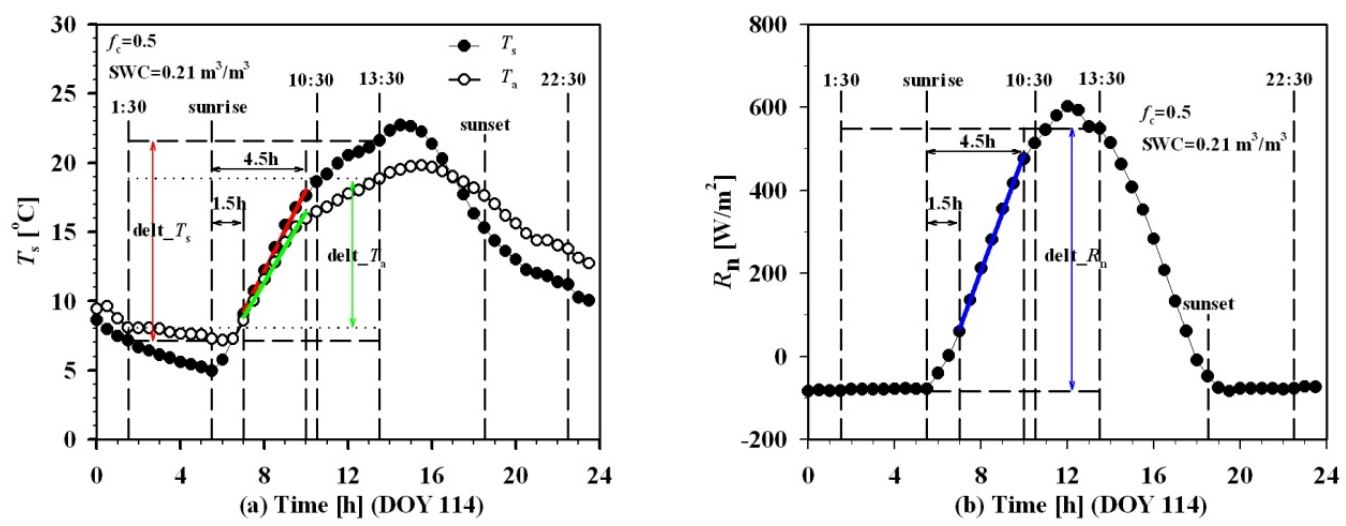

From the analysis based on the ALEX-simulated data, there is a strong linear correlation between the values of $\left(T_{\mathrm{s}}{ }^{\prime}(t)-T_{\mathrm{a}}{ }^{\prime}(t)\right) / R_{\mathrm{n}}{ }^{\prime}(t)$ and $\left(\Delta T_{\mathrm{s}}-\Delta T_{\mathrm{a}}\right) / \Delta R_{\mathrm{n}}$ (see Figure $7 \mathrm{a}, \Delta T_{\mathrm{s}}, \Delta T_{\mathrm{a}}$, and $\Delta R_{\mathrm{n}}$ are the differences of $T_{\mathrm{s}}, T_{\mathrm{a}}$, and $R_{\mathrm{n}}$ between 1:30 P.M./10:30 A.M. and 1:30 A.M./10:30 P.M., respectively.). From in situ measurements at the Yucheng station during the wheat growth period in 2012, the similar results are obtained (see Figure $7 \mathrm{~b}$ ). The values of $\left(T_{\mathrm{s}}{ }^{\prime}(t)-T_{\mathrm{a}}{ }^{\prime}(t)\right) / R_{\mathrm{n}}{ }^{\prime}(t)$ are almost positively proportioned to the values of $\left(\Delta T_{\mathrm{s}}-\Delta T_{\mathrm{a}}\right) / \Delta R_{\mathrm{n}}$, and $R^{2}$ of linear least square fit is greater than 0.8 (see Table 1). The purpose of selecting these moments at 1:30 P.M./10:30 A.M. (MODIS/Aqua or MODIS/Terra daytime overpass time) and 1:30 A.M./10:30 P.M. (MODIS/Aqua or MODIS/Terra nighttime overpass time) was to make this method applicable to MODIS data. The underlying physical mechanism of the linear correlation between $\left(T_{\mathrm{s}}^{\prime}(t)-T_{\mathrm{a}}{ }^{\prime}(t)\right) / R_{\mathrm{n}}{ }^{\prime}(t)$ and $\left(\Delta T_{\mathrm{s}}-\Delta T_{\mathrm{a}}\right) / \Delta R_{\mathrm{n}}$ is that the change rate of $T_{\mathrm{s}}$ during the morning and its day-night difference are all strongly related to soil moisture or thermal inertia [48]. Therefore, daily EF can be parameterized as Equation (13) as follows,

$$
E F_{\text {daily }} \approx 1-\left(A \times f_{\mathrm{c}}^{2}+B \times f_{\mathrm{c}}+C\right) \frac{\Delta T_{s}-\Delta T_{\mathrm{a}}}{\Delta R_{\mathrm{n}}}
$$

It is noted that Equations (12,13) have a similar form but with different inputs (i.e., $\left(T_{\mathrm{s}}{ }^{\prime}(t)-T_{\mathrm{a}}{ }^{\prime}(t)\right) / R_{\mathrm{n}}{ }^{\prime}(t)$ or $\left.\left(\Delta T_{\mathrm{s}}-\Delta T_{\mathrm{a}}\right) / \Delta R_{\mathrm{n}}\right)$. Therefore, coefficients $A, B$, and $C$ in Equation (13) are different from the values of $A, B$, and $C$ in Equation (12). For estimating daily EF by Equation (12), geostationary meteorological satellites could provide a good estimate of $\left(T_{\mathrm{s}}{ }^{\prime}(t)-T_{\mathrm{a}}{ }^{\prime}(t)\right) / R_{\mathrm{n}}{ }^{\prime}(t)$, whereas Equation (13) can accommodate near-polar orbiting satellite data, e.g., MODIS/Terra, MODIS/Aqua. The same location on the Earth can be observed at least four times around 1:30 A.M, 10:30 A.M., 1:30 P.M., and 10:30 P.M. at local solar time in a day by the MODIS sensor. As a result, there are four different input schemes for Equation (13), i.e., the differences between 1:30 P.M. and 1:30 A.M., the differences between 10:30 A.M. and 10:30 P.M., the differences between 10:30 A.M. and 1:30 A.M., 
and the differences between 1:30 P.M. and 10:30 P.M.. Different input schemes have different coefficients. For convenience, Equation (13) also represents Equation (12) in the following study. Theoretically, the coefficients in Equation (13) would vary with atmospheric conditions. For each atmosphere, coefficients can be obtained by using data with different $f_{\mathrm{c}}$ and SWC conditions simulated from a soil-vegetation-atmosphere transfer (SVAT) model, and the procedure for obtaining coefficients is shown in Figure 8. In this study, the ALEX model is used. More details about ALEX simulation can be referred to in Appendix. Only the data of daily EF larger than 0 and less than 1 were selected to derive the coefficients in Equation (13) by the least square method. After obtaining the coefficients, daily EF can be calculated by Equation (13). For ALEX-simulated data driven by different atmospheric conditions from four sites (details about atmospheric forcing and these sites are given in Appendix), results from Equation (13) with different input schemes for four sites are listed in Table 2 . The $R^{2}$ of daily EF estimates from the developed parameterization scheme with respect to the values from the ALEX model is generally higher than 0.8, and the RMSE is $\sim 0.1$. Among all input schemes, the inputs from the differences between 1:30 P.M. and 1:30 A.M. (around MODIS/Aqua daytime and nighttime overpass times) can generate better results than other inputs schemes.

Figure 7. Relationship between the values of $\left(T_{\mathrm{s}}^{\prime}(t)-T_{\mathrm{a}}{ }^{\prime}(t)\right) / R_{\mathrm{n}}{ }^{\prime}(t)$ and $\left(\Delta T_{\mathrm{s}}-\Delta T_{\mathrm{a}}\right) / \Delta R_{\mathrm{n}}$ for (a) ALEX-simulated data driven by the atmospheric forcing at the Yucheng station in 2010, and (b) in situ measurements at the Yucheng station during the wheat growth period in 2012.
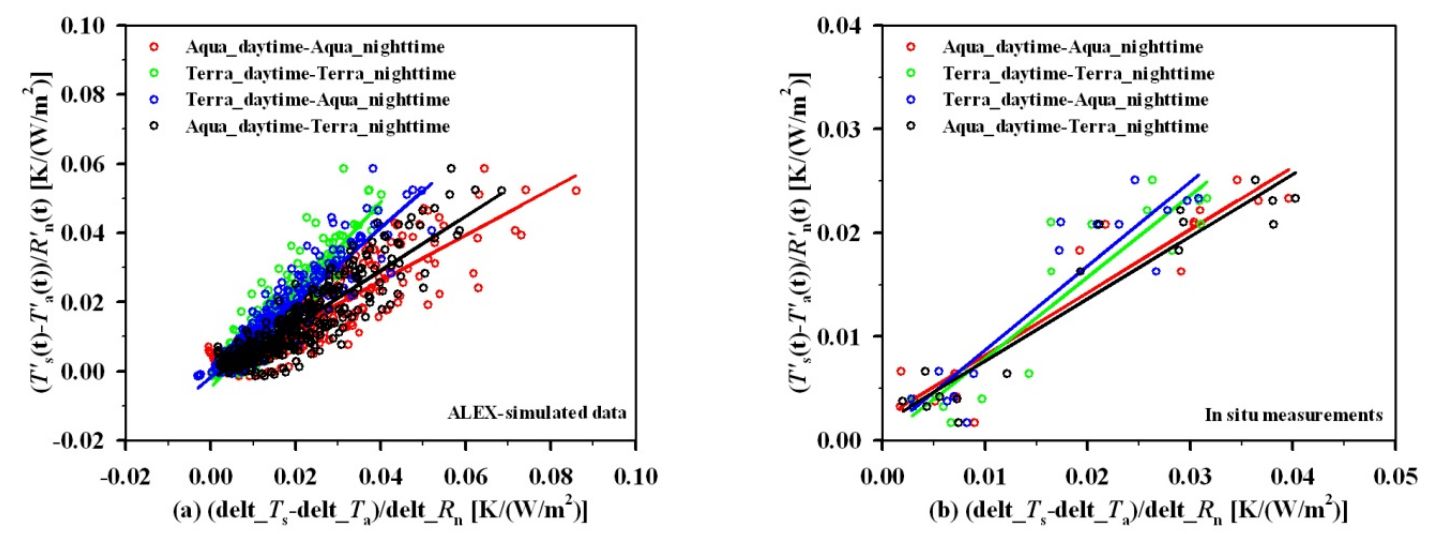

Table 1. Statistics of relationships between the values of $\left(T_{\mathrm{s}}^{\prime}(t)-T_{\mathrm{a}}^{\prime}(t)\right) / R_{\mathrm{n}}{ }^{\prime}(t)$ and $\left(\Delta T_{\mathrm{s}}-\Delta T_{\mathrm{a}}\right) / \Delta R_{\mathrm{n}}$ (Y denotes the value of $\left(T_{\mathrm{s}}^{\prime}(t)-T_{\mathrm{a}}^{\prime}(t)\right) / R_{\mathrm{n}}{ }^{\prime}(t)$, and $\mathrm{X}$ is the value of $\left.\left(\Delta T_{\mathrm{s}}-\Delta T_{\mathrm{a}}\right) / \Delta R_{\mathrm{n}}\right)$

\begin{tabular}{lllll}
\hline Data & Inputs & Linear Relationships & $\boldsymbol{R}^{\mathbf{2}}$ & RMSE \\
\hline \multirow{4}{*}{ ALEX-simulated data } & Aqua daytime-Aqua nighttime & $\mathrm{Y}=0.6619 \mathrm{X}-0.0003$ & 0.808 & 0.0047 \\
& Terra daytime-Terra nighttime & $\mathrm{Y}=1.3435 \mathrm{X}-0.0046$ & 0.874 & 0.0038 \\
& Terra daytime-Aqua nighttime & $\mathrm{Y}=1.0790 \mathrm{X}-0.0017$ & 0.882 & 0.0037 \\
& Aqua daytime-Terra nighttime & $\mathrm{Y}=0.7858 \mathrm{X}-0.0023$ & 0.821 & 0.0045 \\
& Aqua daytime-Aqua nighttime & $\mathrm{Y}=0.6066 \mathrm{X}-0.0021$ & 0.891 & 0.0029 \\
& Terra daytime-Terra nighttime & $\mathrm{Y}=0.7854 \mathrm{X}-0.0001$ & 0.827 & 0.0036 \\
& Terra daytime-Aqua nighttime & $\mathrm{Y}=0.8130 \mathrm{X}-0.0006$ & 0.853 & 0.0033 \\
& Aqua daytime-Terra nighttime & $\mathrm{Y}=0.5996 \mathrm{X}-0.0017$ & 0.894 & 0.0028 \\
\hline
\end{tabular}


Figure 8. Flow chart for obtaining the coefficients in Equation (13) using the SVAT-simulated data.

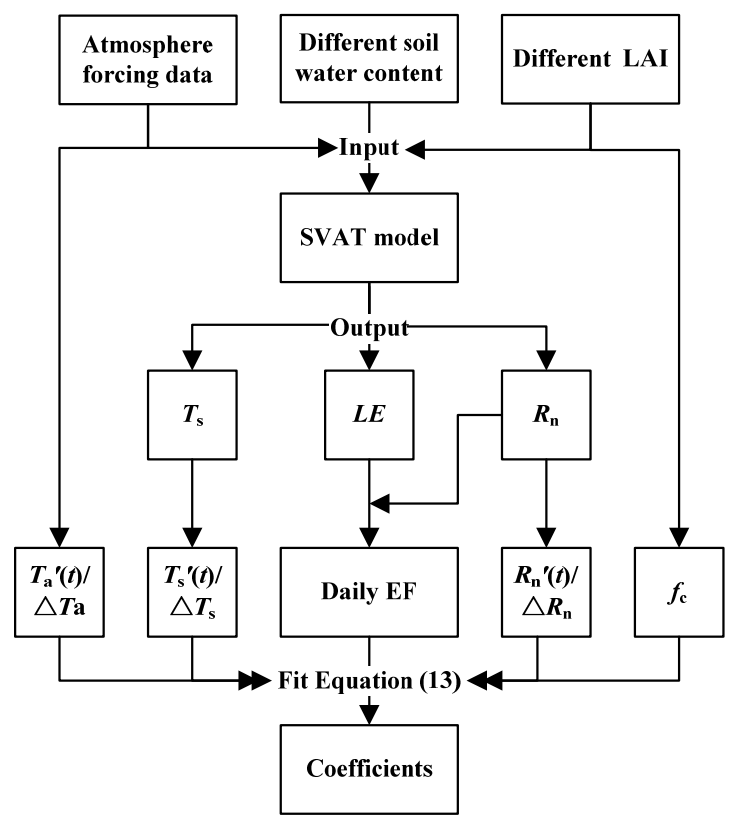

Table 2. Results from Equation (13) with different input schemes for ALEX-simulated data driven by different atmospheric conditions from four sites.

\begin{tabular}{ccccc}
\hline Sites & Inputs & $R^{2}$ & RMSE & BIAS \\
\hline \multirow{4}{*}{ Yucheng } & Change rate during the morning & 0.817 & 0.107 & 0.020 \\
& Aqua daytime-Aqua nighttime & 0.878 & 0.083 & -0.002 \\
& Terra daytime-Terra nighttime & 0.810 & 0.103 & -0.001 \\
& Terra daytime-Aqua nighttime & 0.869 & 0.086 & 0.007 \\
& Aqua daytime-Terra nighttime & 0.835 & 0.098 & -0.009 \\
& Change rate during the morning & 0.806 & 0.106 & 0.023 \\
Goodwind & Aqua daytime-Aqua nighttime & 0.847 & 0.093 & 0.019 \\
& Terra daytime-Terra nighttime & 0.787 & 0.129 & 0.045 \\
& Terra daytime-Aqua nighttime & 0.826 & 0.106 & 0.029 \\
& Aqua daytime-Terra nighttime & 0.840 & 0.098 & 0.023 \\
Cottonwood & Change rate during the morning & 0.787 & 0.124 & 0.029 \\
& Aqua daytime-Aqua nighttime & 0.877 & 0.087 & 0.008 \\
& Terra daytime-Terra nighttime & 0.839 & 0.100 & 0.009 \\
& Terra daytime-Aqua nighttime & 0.850 & 0.111 & 0.033 \\
& Aqua daytime-Terra nighttime & 0.860 & 0.093 & -0.007 \\
Change rate during the morning & 0.827 & 0.101 & 0.001 \\
& Aqua daytime-Aqua nighttime & 0.858 & 0.092 & -0.005 \\
& Terra daytime-Terra nighttime & 0.737 & 0.137 & 0.034 \\
& Terra daytime-Aqua nighttime & 0.837 & 0.104 & 0.019 \\
& Aqua daytime-Terra nighttime & 0.823 & 0.103 & -0.005 \\
\hline
\end{tabular}

Coefficients $A, B$, and $C$ obtained by the least square method for five input schemes and 35 atmospheric forcing from four sites are displayed in Figure 9. It is obvious that coefficients $A$ and $B$ 
strongly vary with the different atmospheres, whereas coefficient $C$ is almost invariant with atmosphere. In addition, it can be observed that the increase of $B$ corresponds to the decrease of $C$, and vice versa for many cases. Therefore, an approximate negative relationship between $B$ and $C$ can be inferred. Coefficients $A, B$, and $C$ in Equation (13) can be assumed to be invariant to a certain degree for all selected atmospheric conditions. When the invariant $A, B$, and $C$ are obtained by fitting all ALEX-simulated data for 35 atmospheric conditions, daily EF for different input schemes is finally parameterized as those equations listed in Table 3.

Figure 9. Variations of coefficients $A, B$, and $C$ in the developed parameterization with atmospheric conditions for five different input schemes.
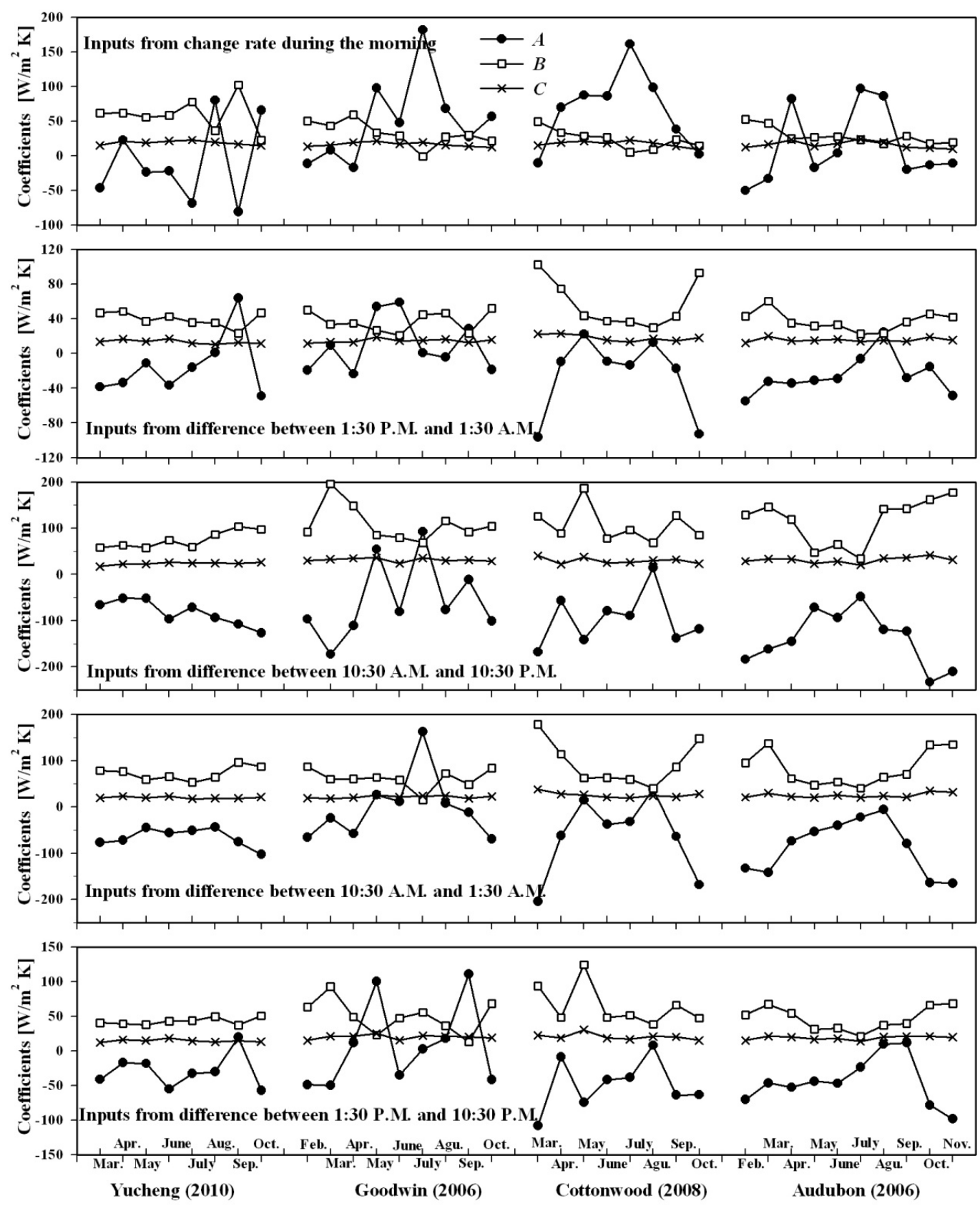
Table 3. Equations of daily EF estimates for different input schemes.

\begin{tabular}{ll}
\hline Inputs & Equations \\
\hline Change rate during the morning & $E F_{\text {daily }}=1-\left(2.06 \times f_{\mathrm{c}}{ }^{2}+38.42 \times f_{\mathrm{c}}+15.74\right) \frac{T_{\mathrm{s}}{ }^{\prime}(t)-T_{\mathrm{a}}{ }^{\prime}(t)}{R_{\mathrm{n}}{ }^{\prime}(t)}$ \\
Aqua daytime-Aqua nighttime & $E F_{\text {daily }}=1-\left(-14.74 \times f_{\mathrm{c}}^{2}+40.01 \times f_{\mathrm{c}}+14.57\right) \frac{\Delta T_{\mathrm{s}}-\Delta T_{\mathrm{a}}}{\Delta R_{\mathrm{n}}}$ \\
Terra daytime-Terra nighttime & $E F_{\text {daily }}=1-\left(-87.38 \times f_{\mathrm{c}}{ }^{2}+83.11 \times f_{\mathrm{c}}+27.19\right) \frac{\Delta T_{\mathrm{s}}-\Delta T_{\mathrm{a}}}{\Delta R_{\mathrm{n}}}$ \\
Terra daytime-Aqua nighttime & $E F_{\text {daily }}=1-\left(-57.02 \times f_{\mathrm{c}}{ }^{2}+71.17 \times f_{\mathrm{c}}+21.58\right) \frac{\Delta T_{\mathrm{s}}-\Delta T_{\mathrm{a}}}{\Delta R_{\mathrm{n}}}$ \\
Aqua daytime-Terra nighttime & $E F_{\text {daily }}=1-\left(-37.35 \times f_{\mathrm{c}}{ }^{2}+49.30 \times f_{\mathrm{c}}+17.45\right) \frac{\Delta T_{\mathrm{s}}-\Delta T_{\mathrm{a}}}{\Delta R_{\mathrm{n}}}$ \\
\hline
\end{tabular}

Figure 10. Comparisons of daily EF estimated by Equations (14-18) with ALEX-simulated actual values based on 35 atmospheric conditions from four sites $((\mathbf{a})$ is for the inputs of change rate during the morning, (b) is for the differences between Aqua daytime and nighttime, (c) is for the differences between Terra daytime and nighttime, (d) is for the differences between Terra daytime and Aqua nighttime, and for the differences between Aqua daytime and Terra nighttime.)
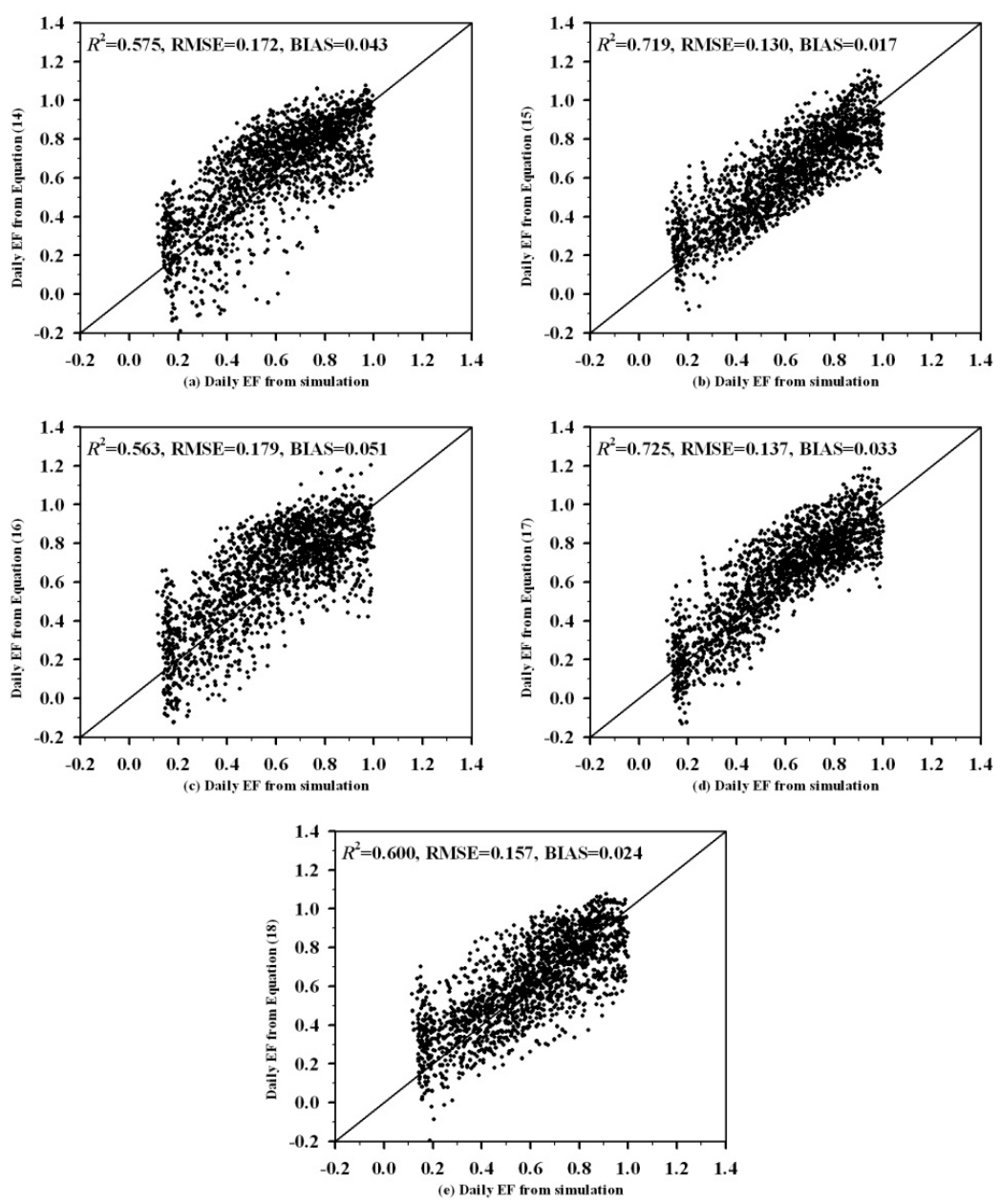
For all simulated data from the ALEX model based on 35 atmospheric conditions at four sites, the daily EF estimates from Equations (14-18) are plotted in Figure 10a-e, respectively. It can be found that Equation (15) with the inputs of the differences between Aqua daytime and nighttime can better estimate daily EF than other input schemes, with an $R^{2}$ of 0.719 , an RMSE of 0.130 , and a mean bias of 0.017. When Equation (17) is used with the inputs of the differences between Terra daytime and Aqua nighttime, daily EF estimates are slightly worse than the results from Equation (15), showing an RMSE of 0.137 and a mean bias of 0.033 . The worst result is from Equation (16) with differences between Terra daytime and nighttime (see also the results shown in Table 2). This indicates that the differences of $T_{\mathrm{s}}, T_{\mathrm{a}}$, and $R_{\mathrm{n}}$ between Aqua/Terra daytime and Aqua nighttime can better reflect the variation of surface heat fluxes in a day than the differences from Terra overpass times. When the change rates of $T_{\mathrm{s}}, T_{\mathrm{a}}$, and $R_{\mathrm{n}}$ during the morning are used as inputs, the result from Equation (14) is not satisfied. On the one hand, the error may be from the weak ability of change rate of $T_{\mathrm{s}}, T_{\mathrm{a}}$, and $R_{\mathrm{n}}$ during the morning reflecting surface heat fluxes, and on the other hand, the approximation of linear relationship of $T_{\mathrm{s}}, T_{\mathrm{a}}$, and $R_{\mathrm{n}}$ with time during the morning also brings certain errors in daily EF estimates. Therefore, for the determination of daily EF, Equation (15) with the inputs of the differences between Aqua daytime and nighttime is recommended.

\section{Data}

To further validate Equation (15) for daily EF estimation, input variables of $\Delta T_{\mathrm{s}}, \Delta T_{\mathrm{a}}, \Delta R_{\mathrm{n}}$, and $f_{\mathrm{c}}$ from in situ measurements and MODIS/Aqua products would be applied.

\subsection{In situ Measurements}

In situ measurements, including meteorological variables, radiation data, and fluxes data, are from the Yucheng station $\left(36.8291^{\circ} \mathrm{N}, 116.5703^{\circ} \mathrm{E}\right)$ in North China. Considering that the assumption of self-preservation EF during daytime may not be valid under the conditions of low solar radiation and air humidity, days with daily average incoming solar radiation $<200 \mathrm{~W} / \mathrm{m}^{2}$ and average relative humidity of air $<20 \%$ were excluded. Daily average incoming solar radiation $<200 \mathrm{~W} / \mathrm{m}^{2}$ generally occurred in the winter or the cloud skies. Based on the available remotely sensed data and in situ measurements, 16 clear days during the wheat growth period in 2012 were finally selected. Surface characteristics of the Yucheng station during the wheat growth period in 2012, i.e., $f_{\mathrm{c}}$ and crop height, are shown in Figure 11. $f_{\mathrm{c}}$ is calculated by weekly measured leaf area index (LAI) from a portable leaf area meter (LI-3000) with the assumption of a random and spherical leaf angle distribution, i.e., $f_{\mathrm{c}}=1-\exp (-0.5 \mathrm{LAI})$. Meteorological variables were routinely measured at the heights of $2.89 \mathrm{~m}$. Radiation data, including downwelling and upwelling shortwave and longwave radiations, were from a CNR-1 radiometer installed at the height of $3.98 \mathrm{~m}$. $T_{\mathrm{s}}$ is not measured at the surface, which is calculated by the measured downwelling and upwelling longwave radiation with a surface emissivity of 0.98 in this study. $H$ and $L E$ were observed from an eddy covariance (EC) system installed at the height of $2.68 \mathrm{~m}$. $G$ was measured by a single HFP-01 soil heat flux plate at $2 \mathrm{~cm}$ below the surface. All data are at a $30-$ min interval. 
Figure 11. Surface characteristics of the Yucheng station during the wheat growth period in 2012.

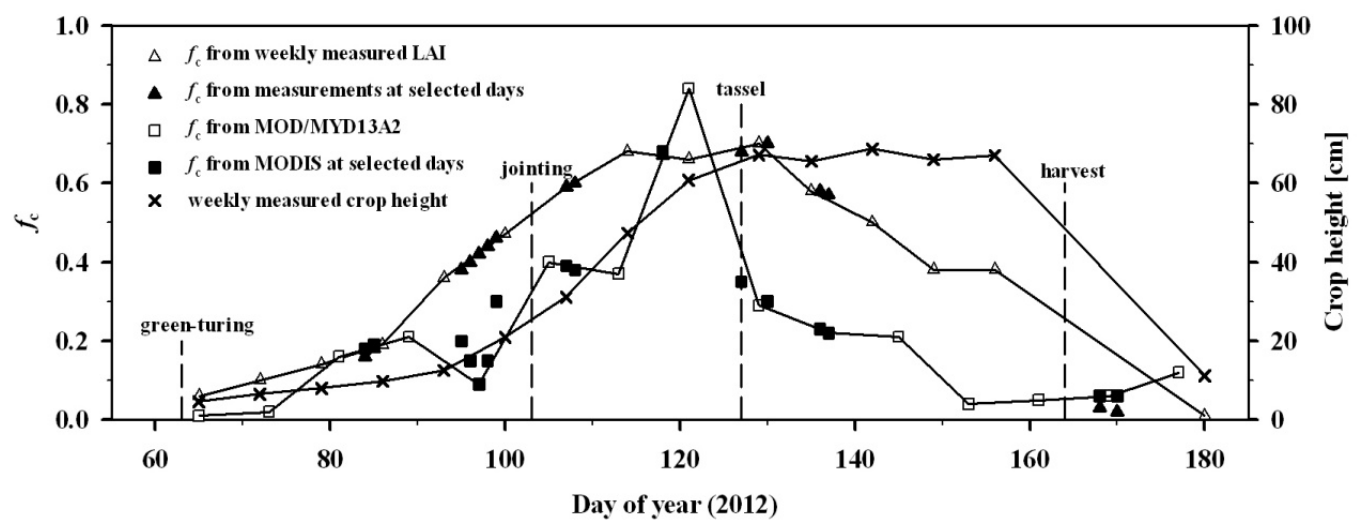

\subsection{Remotely Sensed Data}

Remotely sensed data used in this study include MYD021KM, MYD03, MYD05_L2, MYD11_L2, and MOD13A2/MYD13A2 products. MYD021KM, MYD03, MYD11_L2 and MYD05_L2 are used to estimate $R_{\mathrm{n}}$ at Aqua daytime and nighttime overpass times by the methods proposed by Tang et al. [49,50]. Because there is no incoming solar radiation at nighttime, $R_{\mathrm{n}}$ at Aqua nighttime overpass time equal to the net longwave radiation from Tang and Li's method [50]. Both MOD13A2 and MYD13A2 NDVI products are jointly used to calculate $f_{\mathrm{c}}$ every eight days using the formula proposed by Carlson and Ripley [51], i.e.,

$$
f_{c}=\left(\frac{N D V I-N D V I_{\min }}{N D V I_{\max }-N D V I_{\min }}\right)^{2}
$$

where $N D V I_{\max }$ and $N D V I_{\min }$ are assigned to be 0.86 and 0.2 , respectively, according to the study of Prihodko and Goward [52].

\section{Results and Discussions}

\subsection{Daily EF Estimates with In situ Measurements as Inputs}

When $\Delta T_{\mathrm{s}}, \Delta T_{\mathrm{a}}, \Delta R_{\mathrm{n}}$, and $f_{\mathrm{c}}$ required by Equation (15) are from measurements at the Yucheng station during the wheat growth period in 2012, daily EF estimates are shown in Figure 12a. Compared with the measured daily EF that is calculated by $L E$ from EC and $R_{\mathrm{n}}$ from CNR-1 radiometer (see open squares in Figure 12a), the serious discrepancies appear. Two main reasons can result in the discrepancies: one is from the lack of energy-balance closure in EC-based measurements, and the other is from errors in $f_{\mathrm{c}}$ measurements. As shown in Figure 13, at the daily scale, the RMSE of energy balance closure from EC measurements is $17.0 \mathrm{~W} / \mathrm{m}^{2}$. When daily average $R_{\mathrm{n}}-G$ is under $100 \mathrm{~W} / \mathrm{m}^{2}$, daily average $H+L E$ from EC measurements is generally higher than daily average $R_{\mathrm{n}}-G$, whereas for those cases of daily average $R_{\mathrm{n}}-G$ greater than $100 \mathrm{~W} / \mathrm{m}^{2}$, EC-measured $H+L E$ is less than the values of $R_{\mathrm{n}}-G$. The residual energy (RE) method and the Bowen ratio (BR) method are often used to correct the lack of energy balance closure from EC measurements. RE method is to assume that the 
imbalance energy is due to the underestimation of $L E$ measurements, whereas BR method is to partition the imbalance energy into $H$ and $L E$ according to Bowen ratio [53]. After EC-measured $L E$ was corrected by RE and BR methods, the daily EF estimates can be improved to a certain extent (see black squares and cross symbols in Figure 12a) with an $R^{2}$ of $\sim 0.6$ and an RMSE of $\sim 0.24$. From Figure 11, it can be observed that $f_{\mathrm{c}}$ from MODIS is different from measured values, and is underestimated for most of days. However, $f_{\mathrm{c}}$ from LAI measured by LI-3000 at a point scale was not able to reflect the vegetation cover at large scales. Therefore, $f_{\mathrm{c}}$ from MODIS NDVI products instead of ground-based measurements was also applied to Equation (15). Results in Figure 12b show that daily EF estimates from in situ measurements but $f_{\mathrm{c}}$ from MODIS data as inputs are closer to the EF measurements corrected by RE method with an $R^{2}$ of 0.857 , an RMSE of 0.119 , and a mean bias of 0.049. The results are comparable with the accuracy of Equation (15) driven by the ALEX-simulated data shown in Figure 10b. Therefore, if input variables are accurate, Equation (15) with the differences of $T_{\mathrm{a}}, T_{\mathrm{s}}$ and $R_{\mathrm{n}}$ between 1:30 P.M. and 1:30 A.M. as inputs should give reasonable daily EF estimates.

Figure 12. Comparisons of daily EF estimates (a) from in situ measurements as inputs and (b) from in situ measurements but $\mathrm{f}_{\mathrm{c}}$ from MODIS data as inputs with measured daily EF.
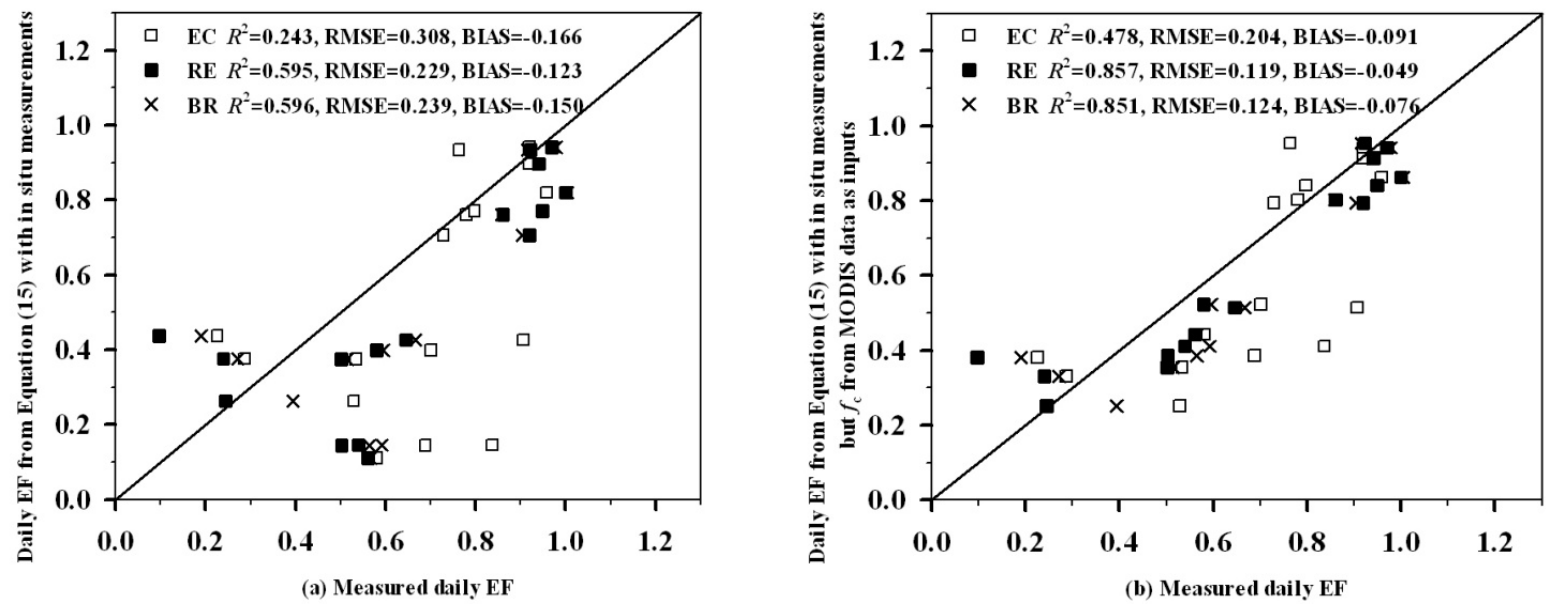

Figure 13. Closure of energy balance from EC measurements at daily scale.

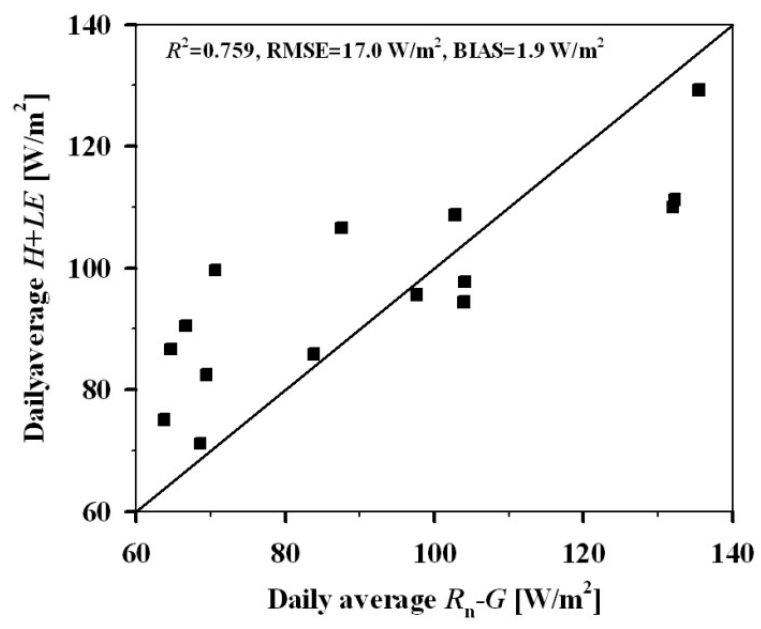


To understand the impact of error in input variables of Equation (15) on daily EF estimates, a sensitivity and error analysis based on in situ measurements but $f_{\mathrm{c}}$ from MODIS data were performed. Each input variable varies under a given set of reference values, a $1 \mathrm{~K}$ step and the upper and lower limits of $\pm 5 \mathrm{~K}$ for $\Delta T_{\mathrm{s}}$ and $\Delta T_{\mathrm{a}}$, a $50 \mathrm{~W} / \mathrm{m}^{2}$ step and the $\pm 250 \mathrm{~W} / \mathrm{m}^{2}$ range for $\Delta R_{\mathrm{n}}$, and a 0.1 step and the \pm 0.5 range for $f_{\mathrm{c}}$. The range of variations and the averaged variations in daily EF estimates at each step of $\Delta T_{\mathrm{s}}, \Delta T_{\mathrm{a}}, \Delta R_{\mathrm{n}}$, and $f_{\mathrm{c}}$ are displayed in Figure $14 \mathrm{a}-\mathrm{d}$, respectively. In general, EF in Equation (15) is negatively correlated to $\Delta T_{\mathrm{s}}$ and $f_{\mathrm{c}}$, and positively correlated to $\Delta T_{\mathrm{a}}$ and $\Delta R_{\mathrm{n}}$. The same error in $\Delta T_{\mathrm{s}}$ and $\Delta T_{\mathrm{a}}$ leads to the same error for daily EF estimates. $2 \mathrm{~K}$ variations in $\Delta T_{\mathrm{s}}$ and $\Delta T_{\mathrm{a}}$ lead to an averaged variation $<0.1$ in daily EF estimates. Error in EF caused by the underestimation of $\Delta R_{\mathrm{n}}$ is generally higher than the error caused by the overestimation of $\Delta R_{\mathrm{n}}$, but the underestimation of $100 \mathrm{~W} / \mathrm{m}^{2}$ in $\Delta R_{\mathrm{n}}$ leads to the averaged error in $\mathrm{EF}<0.1$. In addition, the variation of 0.2 in $f_{\mathrm{c}}$ also leads to the variation of $\sim 0.1$ in EF. The range of variations in daily EF estimation caused by the error in inputs variables indicates that daily EF estimates from Equation (15) may be more sensitive to $f_{\mathrm{c}}$ and the underestimation of $\Delta R_{\mathrm{n}}$ than other inputs.

Figure 14. Variations in daily EF estimates caused by the variations in input variables (a) $\Delta T_{\mathrm{s}}$, (b) $\Delta T_{\mathrm{a}}$, (c) $\Delta R_{\mathrm{n}}$, and (d) $f_{\mathrm{c}}$ (the filled squares denote the averaged variations in daily EF estimates, whereas the error bars represent the range of variations.).

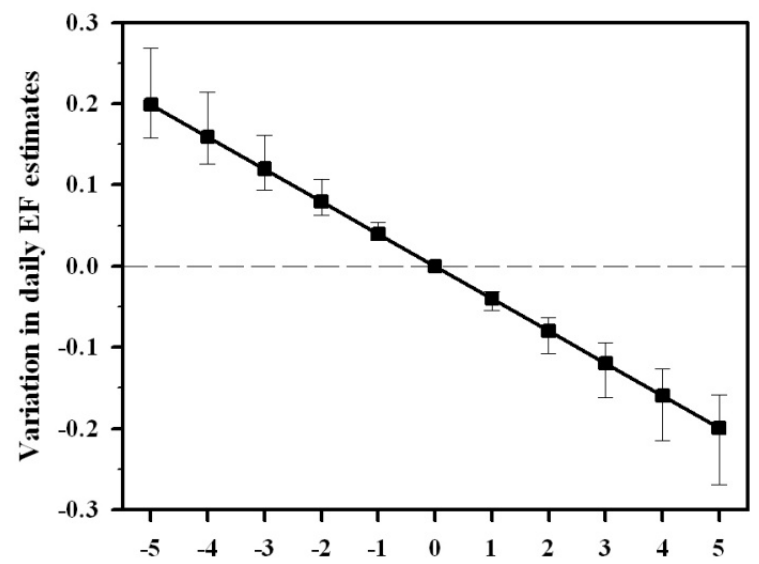

(a) Variation in delt_ $T_{\mathrm{s}}[\mathrm{K}]$

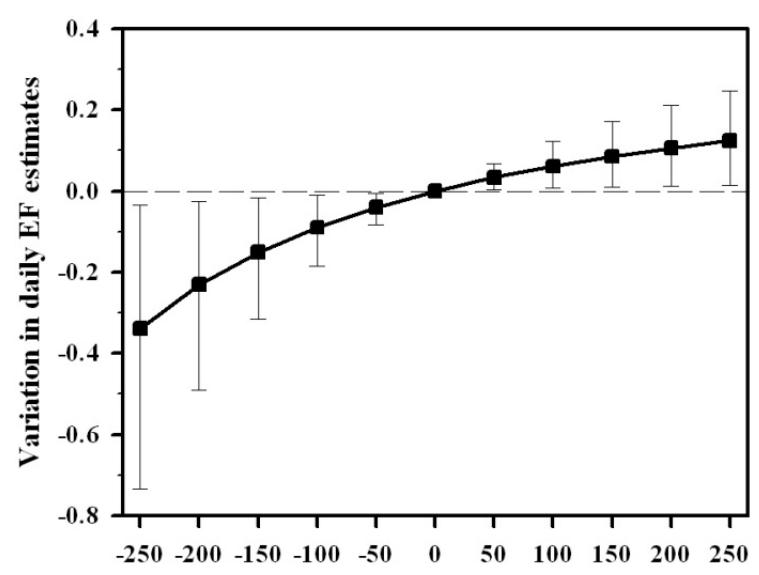

(c) Variation in delt_Rn $\left[\mathrm{W} / \mathrm{m}^{2}\right]$

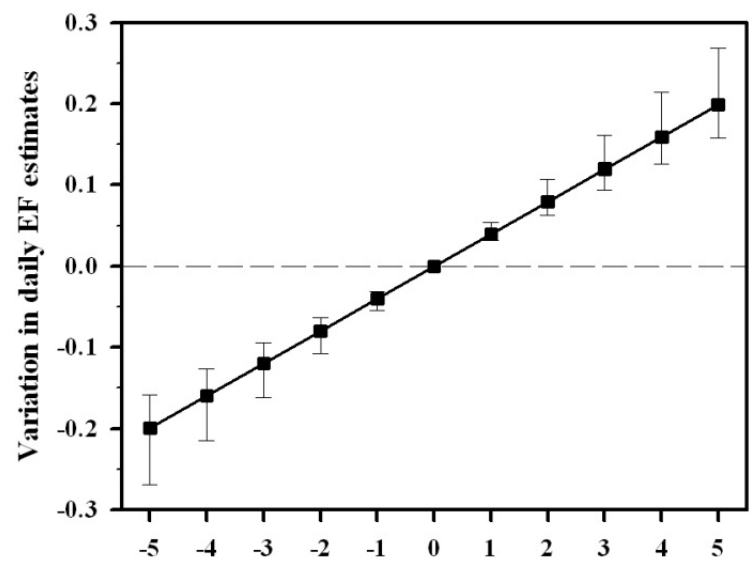

(b) Variation in delt_ $T_{\mathrm{a}}[\mathrm{K}]$

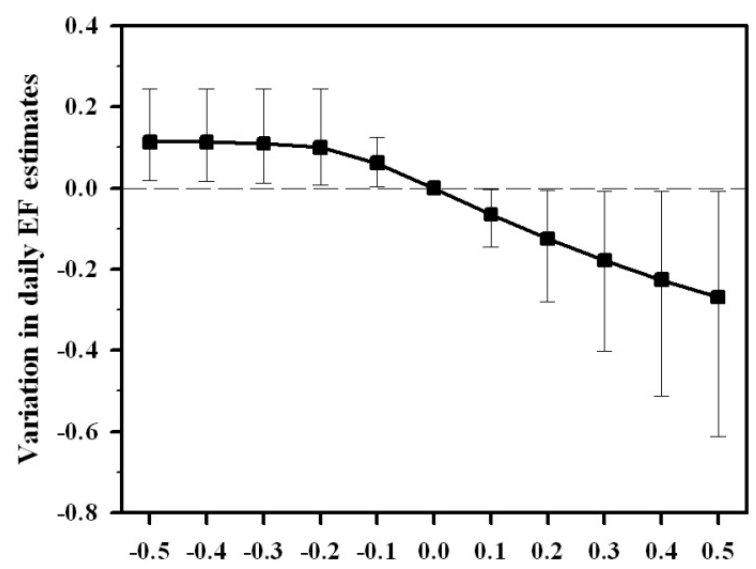

(d) Variation in $f_{\text {c }}$ 


\subsection{Application to Satellite Data}

A flowchart showing procedures for daily EF estimation from MODIS/Aqua data is presented in Figure 15. Input variables $\Delta T_{\mathrm{s}}, \Delta R_{\mathrm{n}}$, and $f_{\mathrm{c}}$ required by Equation (15) are all obtained from MODIS/Aqua products, whereas $\Delta T_{\mathrm{a}}$ is from in situ measurements. Although MYD07_L2 products can provide atmosphere profile data, the retrieved atmosphere temperature at the bottom of the atmosphere was not used in this study because of different spatial resolutions between the MYD07_L2 product $(5 \mathrm{~km})$ and other MODIS/Aqua products $(1 \mathrm{~km})$ used in this study and less available data at the Yucheng station.

Figure 15. Flowchart of for daily EF estimation.

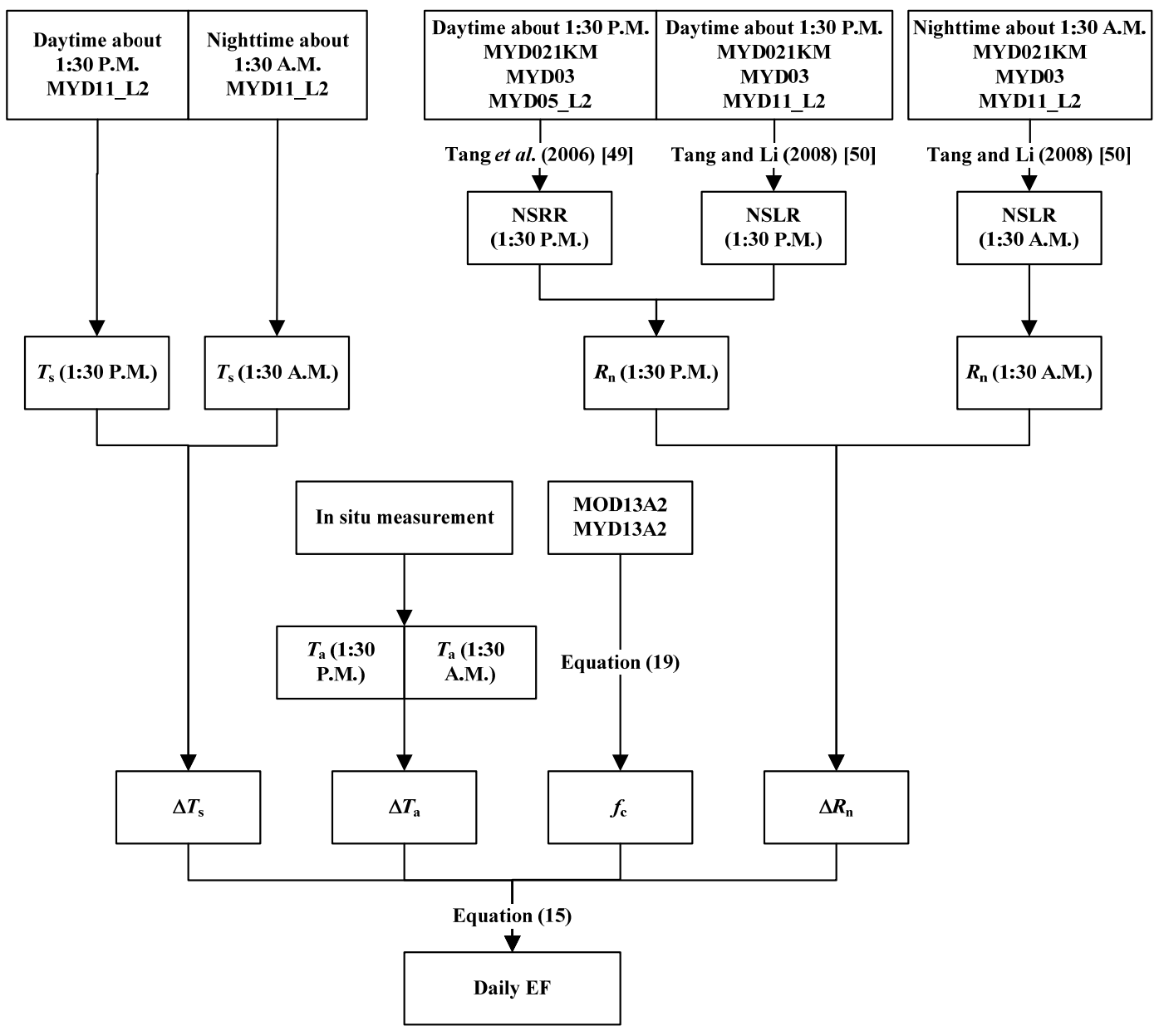

For the selected 16 clear days at the Yucheng station during wheat growth period in 2012, daily EF calculated by Equation (15) from MODIS/Aqua data is shown in Figure 16. Compared with the daily EF from EC measurements and the values corrected by the RE or BR method, RMSE is about 0.24. For the majority of cases, the results estimated by Equation (15) are generally consistent with the measurements, but several large discrepancies deteriorate the overall results. One of the reasons of the discrepancies between daily EF estimates from remotely sensed data and the measurements may be ascribed to the difference in spatial scale between the MODIS observation and EC measurements. The nominal spatial resolution of MODIS senor at the thermal infrared bands is $1 \mathrm{~km}$, whereas the footprint 
of EC at the height of $2.68 \mathrm{~m}$ would be far less than MODIS observation scale [3,54]. Because of the heterogeneous nature of land surface, surface heat fluxes vary at spatial scales [20]. Therefore, the EC-measured surface fluxes may not represent the values at MODIS pixel scale. Although it is not appropriate to compare EF estimates from MODIS data with EC measurements because of different scales of observation, only the result shown in Figure 16 is given because of the lack of surface flux observation at MODIS pixel scale.

Figure 16. Comparisons of daily EF estimates from MODIS data with in situ measurements.

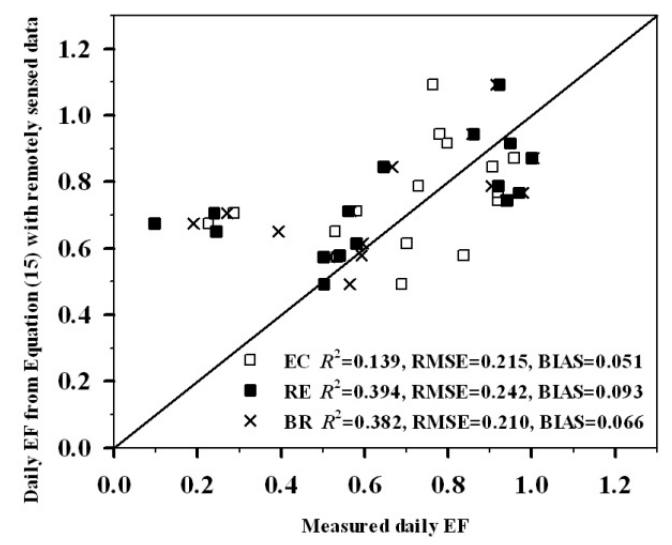

Figure 17. Comparisons of (a) $T_{\mathrm{s}}$ and (b) $R_{\mathrm{n}}$ from MODIS/Aqua products with the corresponding measurements from CNR-1.

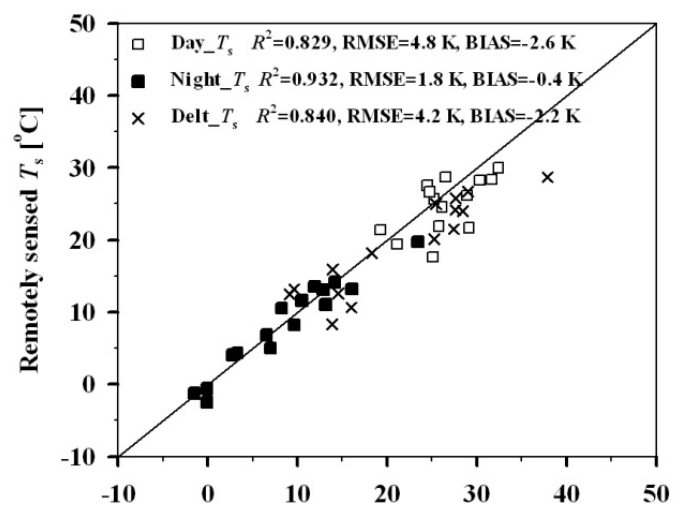

(a) Measured $T_{\mathrm{s}}\left[{ }^{\circ} \mathrm{C}\right]$

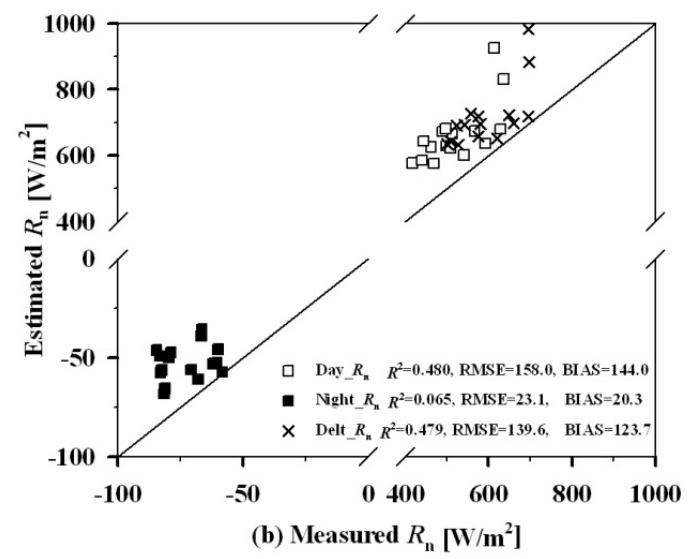

(b) Measured $R_{\mathrm{n}}\left[\mathrm{W} / \mathrm{m}^{2}\right]$

In addition, retrieval errors in $T_{\mathrm{s}}$ and $R_{\mathrm{n}}$ also lead to the discrepancies between daily EF estimates from Equation (15) and EC measurements. $T_{\mathrm{s}}$ is directly from the MYD11_L2 product, which is produced daily at 5-minute increments using the generalized split-window algorithm [55]. Compared with the measured $T_{\mathrm{s}}$ that is calculated by CNR-1 measurements, MYD11_L2 products underestimated $T_{\mathrm{s}}$ by $2.6 \mathrm{~K}$ at Aqua daytime overpass time and by $0.4 \mathrm{~K}$ at nighttime overpass time. As a result, the underestimation in $\Delta T_{\mathrm{s}}$ is reduced to $2.2 \mathrm{~K}$ with an $R^{2}$ of 0.840 and an RMSE of $4.2 \mathrm{~K}$ (see Figure 17a). Though both $R_{\mathrm{n}}$ at Aqua daytime and nighttime overpass times estimated by Tang's method are all higher than the measured $R_{\mathrm{n}}$ (see Figure $17 \mathrm{~b}$ ), the quantity of overestimation of 
123.7 W/m $\mathrm{m}^{2}$ in $\Delta R_{\mathrm{n}}$ is still large because of the obvious overestimation of $R_{\mathrm{n}}$ at Aqua daytime overpass time. The quantity of $R_{\mathrm{n}}$ at nighttime is negative, so the value of $\Delta R_{\mathrm{n}}$ is greater than $R_{\mathrm{n}}$ at daytime.

\subsection{Comparison with SEBS-Estimated EF}

SEBS is a representative one-source energy balance model of estimating surface heat fluxes from remotely sensed data. In the SEBS model, EF is formulated on the basis of the energy balance at limiting cases [9]. Because the limiting cases are calculated by an equation similar to the Penman-Monteith combination equation rather than using the spatial information from remotely sensed data like triangle-type methods, the SEBS model cannot be restricted by the research domain in theory. The SEBS model estimates EF by the one-time observed remotely sensed data. Because of the relatively invariant EF during diurnal cycle, the instantaneous EF during daytime is often considered as the daily EF to estimate daily ET. By using MODIS products at Aqua daytime overpass time, daily EF at the Yucheng station can also be estimated by the SEBS model. From Figure 18a, it can be observed that the daily EF estimated by Equation (15) with remotely sensed data as inputs is well correlated with the SEBS-estimated value with an $R^{2}$ of 0.838 and an RMSE of 0.124 . However, when the difference between $T_{\mathrm{s}}$ and $T_{\mathrm{a}}$ at Aqua daytime overpasses, the time required by the SEBS model is less than 0 , SEBS-estimated EF is greater than 1 and is also greater than EF from Equation (15). When SEBS-estimated EF is compared with the values from in situ measurements, the results shown in Figure $18 \mathrm{~b}$ are inferior to the results from Equation (15) as shown in Figure 16 (see Table 4), and more dispersed data appear. This indicates that the EF estimates from instantaneous inputs are more sensitive to the retrieval error of remotely sensed data at one-time observation, whereas the application of the temporal variation in surface variables can reduce the uncertainties caused by retrieval errors in remotely sensed data. In addition, although daily EF can be approximated by instantaneous EF during daytime, daily EF is essentially different from instantaneous values. Instantaneous EF instead of daily EF would result in some errors, whereas Equation (15) can directly determine daily EF. Equation (15) needs fewer input variables than the SEBS model: only $\Delta T_{\mathrm{s}}, \Delta T_{\mathrm{a}}, \Delta R_{\mathrm{n}}$, and $f_{\mathrm{c}}$ are required. These input variables can be easily obtained from remote sensing. Therefore, Equation (15) has the potential to estimate surface ET at the regional scale.

Figure 18. Comparisons of (a) daily EF estimates from Equation (15) with SEBS-estimated EF based on MODIS/Aqua data, and of (b) SEBS-estimated EF with measured daily EF.
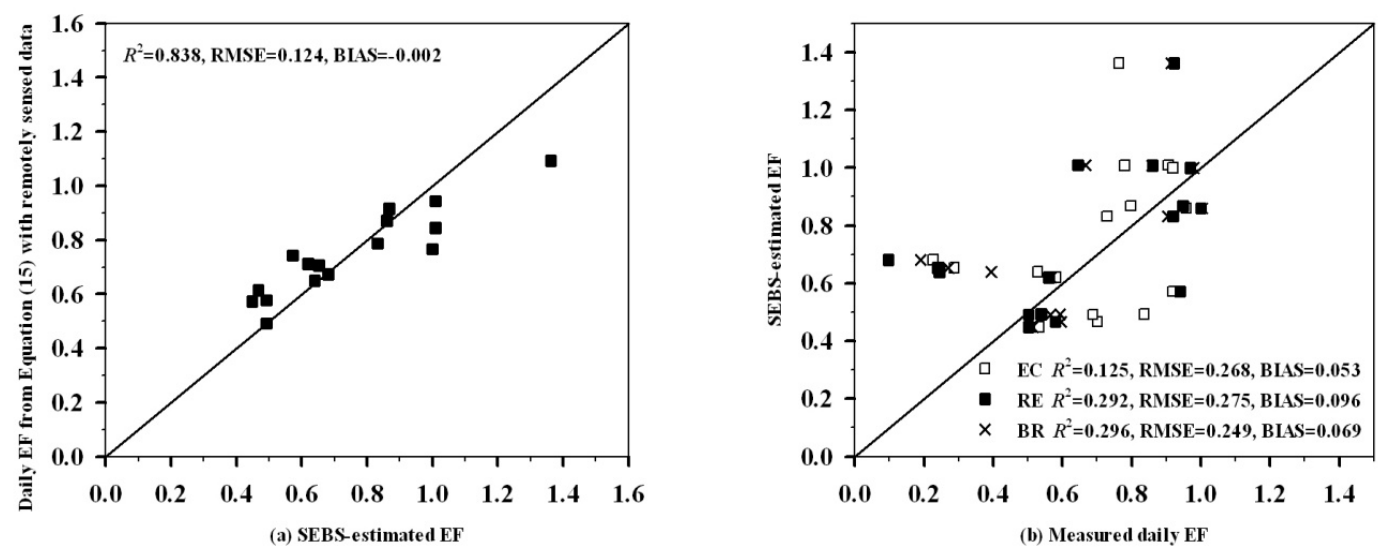
Table 4. Comparisons of the remotely sensed daily EF estimated by our proposed method and the SEBS model with EC-measured, RE and BR-corrected EF.

\begin{tabular}{|c|c|c|c|c|c|c|c|c|c|}
\hline & \multicolumn{3}{|l|}{ EC } & \multicolumn{3}{|l|}{ RE } & \multicolumn{3}{|l|}{ BR } \\
\hline & $R^{2}$ & RMSE & BIAS & $R^{2}$ & RMSE & BIAS & $R^{2}$ & RMSE & BIAS \\
\hline New method & 0.139 & 0.215 & 0.051 & 0.394 & 0.242 & 0.093 & 0.382 & 0.210 & 0.066 \\
\hline SEBS & 0.125 & 0.268 & 0.053 & 0.292 & 0.275 & 0.096 & 0.296 & 0.249 & 0.069 \\
\hline
\end{tabular}

\section{Conclusion}

On the basis of surface energy balance and the assumption of self-preservation EF (evaporative fraction) during daytime, this study developed a new parameterization scheme for deriving daily EF from temporal variations of $T_{\mathrm{s}}$ (surface temperature), $T_{\mathrm{a}}$ (air temperature), and $R_{\mathrm{n}}$ (net radiation). Among various input schemes as to temporal variations, the differences of $T_{\mathrm{s}}, T_{\mathrm{a}}$, and $R_{\mathrm{n}}$ between 1:30 P.M. and 1:30 A.M. (around at Aqua overpass times), i.e., $\Delta T_{\mathrm{s}}, \Delta T_{\mathrm{a}}$, and $\Delta R_{\mathrm{n}}$, can produce better estimates for daily EF with an $R^{2}$ (coefficient of determination) of 0.719 and an RMSE (root mean square error) of 0.130 with respect to ALEX (atmosphere-land exchange model)-based estimates. When the input scheme in combination with input variables from ground-based measurements is used to estimate daily EF at the Yucheng station during the wheat growth period in 2012, the results agreed well with the daily EF corrected by RE (residual energy) method with an $R^{2}$ of 0.857 and an RMSE of 0.119 . Sensitivity and error analysis show that variations in input variables of $2 \mathrm{~K}$ in $\Delta T_{\mathrm{s}}$ and $\Delta T_{\mathrm{a}}$, $100 \mathrm{~W} / \mathrm{m}^{2}$ in $\Delta R_{\mathrm{n}}$, and 0.2 in $f_{\mathrm{c}}$ (fractional vegetation cover) could lead to errors $<0.1$ for daily $\mathrm{EF}$ estimates. Although daily EF estimates in combination with remotely sensed inputs are not in good agreement with the measured measurements, they are correlated with results from the SEBS (surface energy balance system) model, and are slightly superior to SEBS-estimated EF with remotely sensed instantaneous inputs.

The developed EF parameterization scheme in this study required $\Delta T_{\mathrm{s}}, \Delta T_{\mathrm{a}}, \Delta R_{\mathrm{n}}$, and $f_{\mathrm{c}}$ as inputs. The input requirements can be satisfied by remotely sensed data from the MODIS sensor or geostationary meteorological satellites. $\Delta T_{\mathrm{s}}, \Delta T_{\mathrm{a}}$ and $\Delta R_{\mathrm{n}}$ rather than absolute $T_{\mathrm{s}}, T_{\mathrm{a}}$ and $R_{\mathrm{n}}$ can diminish uncertainties in surface flux estimates caused by errors in remotely sensed data to a certain degree. Another advantage of the proposed method is that it directly determines daily EF without the need for the calculation of various resistances which requires many surface parameters. Fewer input requirements will enable the developed approach to estimate surface evapotranspiration over data-sparse region or at regional scale because some surface parameters are not easily measured at a large spatial scale. In addition, the accuracy of daily EF estimates is also independent of the errors in daily net radiation estimates.

Because the parameterization scheme for daily EF estimation is developed based on the assumption of self-preservation EF during daytime, when the assumption cannot be met, it may not be applicable to estimating daily EF. Therefore, the method may be more appropriate to estimate surface fluxes under the conditions of clear skies, humid air, and strong solar radiation because of relative invariant $\mathrm{EF}$ at such conditions. The results from ALEX-simulated data and the measurements at the Yucheng station can demonstrate that the coefficients in the proposed parameterization scheme are not sitespecific and do not strongly depend on the atmospheric conditions. However, this is only a preliminary 
conclusion. More validation across various land surface types needs to be performed in the future to further evaluate the robustness of the proposed EF parameterization scheme.

\section{Acknowledgments}

This work was partly supported by the National Natural Science Foundation of China under Grant 41201366 and 41101332 and by the China Postdoctoral Science Foundation funded project under Grant 07Z7602MZ1. Jing Lu is financially supported by the China Scholarship Council for her stay in ICube, Strasbourg, France.

\section{Conflicts of Interest}

The authors declare no conflict of interest.

\section{References}

1. Vinukollu, R.K.V.R.K.; Wood, E.F.; Ferguson, C.R.; Fisher, J.B. Global estimates of evapotranspiration for climate studies using multi-sensor remote sensing data: Evaluation of three process-based approaches. Remote Sens. Environ. 2011, 115, 801-823.

2. Anderson, M.C.; Allen, R.G.; Morse, A.; Kustas, W.P. Use of Landsat thermal imagery in monitoring evapotranspiration and managing water resources. Remote Sens. Environ. 2012, 122, $50-65$.

3. Tang, R.L.; Li, Z.-L.; Jia, Y.; Li, C.; Sun, X.; Kustas, W.P.; Anderson, M.C. An intercomparison of three remote sensing-based energy balance models using Large Aperture Scintillometer measurements over a wheat-corn production region. Remote Sens. Environ. 2011, 115, 3187-3202.

4. Teixeira, A.H. de C.; Bastiaanssen, W.G.M.; Ahmad, M.D.; Bos, M.G. Determining regional actual evapotranspiration of irrigated crops and natural vegetation in the São Francisco River Basin (Brazil) using remote sensing and penman-monteith equation. Remote Sens. 2010, 2, 1287-1319.

5. Ruhoff, A.L.; Paz, A.R.; Collischonn, W.; Aragao, L.E.O.C.; Rocha, H.R.; Malhi, Y.S. A MODIS-based energy balance to estimate evapotranspiration for clear-sky days in Brazilian Tropical Savannas. Remote Sens. 2012, 4, 703-725.

6. Johnson, L.F.; Trout, T.J. Satellite NDVI assisted monitoring of vegetable crop evapotranspiration in California's San Joaquin Valley. Remote Sens. 2012, 4, 439-455.

7. Long, D.; Singh, V.P. A two-source trapezoid model for evapotranspiration (TTME) from satellite imagery. Remote Sens. Environ. 2012, 121, 370-388.

8. Bastiaanssen, W.; Menenti, M.; Feddes, R.; Holtslag, A. A remote sensing surface energy balance algorithm for land (SEBAL). 1. Formulation. J. Hydrol. 1998, 212, 198-212.

9. $\mathrm{Su}, \mathrm{Z}$. The surface energy balance system (SEBS) for estimation of turbulent heat fluxes. Hydrol. Earth Syst. Sci. 2002, 6, 85-99.

10. Norman, J.M.; Kustas, W.P.; Humes, K.S. Source approach for estimating soil and vegetation energy fluxes in observations of directional radiometric surface-temperature. Agric. For. Meteorol. 1995, 77, 263-293. 
11. Li, Z.-L.; Tang, B.H.; Wu, H.; Ren, H.; Yan, G.; Wan, Z. Satellite-derived land surface temperature: Current status and perspectives. Remote Sens. Environ. 2013, 131, 14-37.

12. Wu, H.; Li, Z.-L. Scale issues in remote sensing: A review on analysis, processing and modeling. Sensors 2009, 9, 1768-1793.

13. Li, Z.-L.; Wu, H.; Wang, N.; Qiu, S.; Sobrino, J.A.; Wan, Z.; Tang, B.H.; Yan, G. Land surface emissivity retrieval from satellite data. Int. J. Remote Sens. 2013, 34, 3084-3127.

14. Li, Z.-L.; Tang, R.L.; Wan, Z.; Bi, Y.; Zhou, C.; Tang, B.H.; Yan, G.; Zhang, X. A review of current methodologies for regional evapotranspiration estimation from remotely sensed data. Sensors 2009, 9, 3801-3853.

15. Kalma, J.D.; McVicar, T.R.; McCabe, M.F. Estimating land surface evaporation: A review of methods using remotely sensed surface temperature data. Surv. Geophys. 2008, 29, 421-469.

16. Wang, K.C.; Dickinson, R.E. A review of global terrestrial evapotranspiration: Observation, modeling, climatology, and climatic variability. Rev. Geophys. 2012, doi: 10.1029/2011RG000373.

17. Crago, R.D. Conservation and variability of the evaporative fraction during the daytime. J. Hydrol. 1996, 180, 173-194.

18. Lhomme, J.P.; Elguero, E. Examination of evaporative fraction diurnal behaviour using a soil-vegetation model coupled with a mixed-layer model. Hydrol. Earth Syst. Sci. 1999, 3, 259-270.

19. Gentine, P.; Entekhabi, D.; Polcher, J. The diurnal behavior of evaporative fraction in the soil-vegetation-atmospheric boundary layer continuum. J. Hydrometeorol. 2011, 12, 1530-1546.

20. Lu, J.; Li, Z.-L.; Tang, R.L.; Tang, B.H.; Wu, H.; Yang, F.; Labed, J.; Zhou, G. Evaluating the SEBS-estimated evaporative fraction from MODIS data for a complex underlying surface. Hydrol. Process. 2012, doi: 10.1002/hyp.9440.

21. Nichols, W.E.; Cuenca, R.H. Evaluation of the evaporative fraction for parameterization of the surface energy balance. Water Resour. Res. 1993, 29, 3681-3690.

22. Colaizzi, P.; Evett, S.; Howell, T.; Tolk, J. Comparison of five models to scale daily evapotranspiration from one-time-of-day measurements. Trans. ASAE 2006, 49, 1409-1417.

23. Sugita, M.; Brutsaert, W. Daily evaporation over a region from lower boundary layer profiles measured with radiosondes. Water Resour. Res. 1991, 27, 747-752.

24. Tang, R.L.; Li, Z.-L.; Sun, X. Temporal upscaling of instantaneous evapotranspiration: An intercomparison of fourmethods using eddy covariance measurements and MODIS data. Remote Sens. Environ. 2013, doi: 10.1016/j.rse.2013.07.001.

25. Cammalleri, C.; Anderson, M.; Kustas, W. Upscaling of evapotranspiration fluxes from instantaneous to daytime scales for thermal remote sensing applications. Hydrol. Earth Syst. Sci. 2013, 10, 7325-7350.

26. Jiang, L.; Islam, S. A methodology for estimation of surface evapotranspiration over large areas using remote sensing observations. Geophys. Res. Lett. 1999, 26, 2773-2776.

27. Roerink, G.; Su, Z.; Menenti, M. S-SEBI: A simple remote sensing algorithm to estimate the surface energy balance. Phys. Chem. Earth Part. B Hydrol. Oceans Atmos. 2000, 25, 147-157.

28. Tang, R.L; Li, Z.-L.; Tang, B.H. An application of the Ts-VI triangle method with enhanced edges determination for evapotranspiration estimation from MODIS data in arid and semi-arid regions: Implementation and validation. Remote Sens. Environ. 2010, 114, 540-551. 
29. Anderson, M.C.; Norman, J.M.; Diak, G.R.; Kustas, W.P.; Mecikalski, J.R. A two-source time-integrated model for estimating surface fluxes using thermal infrared remote sensing. Remote Sens. Environ. 1997, 60, 195-216.

30. Norman, J.M.; Kustas, W.P.; Prueger, J.H.; Diak, G.R. Surface flux estimation using radiometric temperature: A dual temperature-difference method to minimize measurement errors. Water Resour. Res. 2000, 36, 2263-2274.

31. Wang, K.C.; Li, Z.Q.; Cribb, M. Estimation of evaporative fraction from a combination of day and night land surface temperatures and NDVI: A new method to determine the Priestley-Taylor parameter. Remote Sens. Environ. 2006, 102, 293-305.

32. Stisen, S.; Sandholt, I.; Norgaard, A.; Fensholt, R.; Jensen, K.H. Combining the triangle method with thermal inertia to estimate regional evapotranspiration-Applied to MSG-SEVIRI data in the Senegal River basin. Remote Sens. Environ. 2008, 112, 1242-1255.

33. Shu, Y.Q.; Stisen, S.; Jensen, K.H.; Sandholt, I. Estimation of regional evapotranspiration over the North China Plain using geostationary satellite data. Int. J. Appl. Earth Obs. 2011, 13, 192-206.

34. Long, D.; Singh, V.P.; Scanlon, B.R. Deriving theoretical boundaries to address scale dependencies of triangle models for evapotranspiration estimation. J. Geophys. Res. 2012, 117, D05113.

35. Long, D.; Singh, V.P. Assessing the impact of end-member selection on the accuracy of satellite-based spatial variability models for actual evapotranspiration estimation. Water Resour. Res. 2013, 49, 2601-2618.

36. Anderson, M.C.; Norman, J.M.; Meyers, T.P.; Diak, G.R. An analytical model for estimating canopy transpiration and carbon assimilation fluxes based on canopy light-use efficiency. Agric. For. Meteorol. 2000, 101, 265-289.

37. Brutsaert, W. Evaporation into the Atmosphere: Theory, History, and Applications; D. Reidel: Dordrecht, The Netherlands, 1982.

38. Kalma, J.; Jupp, D. Estimating evaporation from pasture using infrared thermometry: Evaluation of a one-layer resistance model. Agric. For. Meteorol. 1990, 51, 223-246.

39. Chehbouni, A.; Lo Seen, D.; Njoku, E.; Monteny, B. Examination of the difference between radiative and aerodynamic surface temperatures over sparsely vegetated surfaces. Remote Sens. Environ. 1996, 58, 177-186.

40. Lhomme, J.; Chehbouni, A.; Monteny, B. Sensible heat flux-radiometric surface temperature relationship over sparse vegetation: Parameterizing B-1. Bound.-Lay. Meteorol. 2000, 97, 431-457.

41. Sun, J.; Mahrt, L. Determination of surface fluxes from the surface radiative temperature. J. Atmos. Sci. 1995, 52, 1096-1106.

42. Carlson, T.N.; Buffum, M.J. On estimating total daily evapotranspiration from remote surface temperature measurements. Remote Sens. Environ. 1989, 29, 197-207.

43. Lagouarde, J.-P.; McAneney, K. Daily sensible heat flux estimation from a single measurement of surface temperature and maximum air temperature. Bound.-Lay. Meteorol. 1992, 59, 341-362.

44. Carlson, T.N.; Capehart, W.J.; Gillies, R.R. A new look at the simplified method for remote sensing of daily evapotranspiration. Remote Sens. Environ. 1995, 54, 161-167.

45. Brutsaert, W.; Sugita, M. Application of self-preservation in the diurnal evolution of the surface energy budget to determine daily evaporation. J. Geophys. Res. 1992, 97, 18377-18382. 
46. Daughtry, C.; Kustas, W.; Moran, M.; Pinter, P.; Jackson, R.; Brown, P.; Nichols, W.; Gay, L. Spectral estimates of net radiation and soil heat flux. Remote Sens. Environ. 1990, 32, 111-124.

47. Choudhury, B.J.; Idso, S.B.; Reginato, R.J. Analysis of an empirical model for soil heat flux under a growing wheat crop for estimating evaporation by an infrared-temperature based energy balance equation. Agric. For. Meteorol. 1987, 39, 283-297.

48. Van de Griend, A.A.; Camillo, P.J.; Gurney, R.J. Discrimination of soil physical parameters, thermal inertia, and soil moisture from diurnal surface temperature fluctuations. Water Resour. Res. 1985, 21, 997-1009.

49. Tang, B.H.; Li, Z.-L.; Zhang, R. A direct method for estimating net surface shortwave radiation from MODIS data. Remote Sens. Environ. 2006, 103, 115-126.

50. Tang, B.H.; Li, Z.-L. Estimation of instantaneous net surface longwave radiation from MODIS cloud-free data. Remote Sens. Environ. 2008, 112, 3482-3492.

51. Carlson, T.N.; Ripley, D.A. On the relation between NDVI, fractional vegetation cover, and leaf area index. Remote Sens. Environ. 1997, 62, 241-252.

52. Prihodko, L.; Goward, S.N. Estimation of air temperature from remotely sensed surface observations. Remote Sens. Environ. 1997, 60, 335-346.

53. Twine, T.; Kustas, W.; Norman, J.; Cook, D.; Houser, P.; Meyers, T.; Prueger, J.; Starks, P.; Wesely, M. Correcting eddy-covariance flux underestimates over a grassland. Agric. For. Meteorol. 2000, 103, 279-300.

54. McCabe, M.F.; Wood, E.F. Scale influences on the remote estimation of evapotranspiration using multiple satellite sensors. Remote Sens. Environ. 2006, 105, 271-285.

55. Wan, Z.; Dozier, J. A generalized split-window algorithm for retrieving land-surface temperature from space. IEEE T. Geosci. Remot. 1996, 34, 892-905.

56. Campbell, G.S.; Norman, J.M. Introduction to Environmental Biophysics; Springer Verlag: New York, NY, USA, 1998.

\section{Appendix}

Simulated data used in this study are from an atmosphere-land exchange (ALEX) model. ALEX is a two-source dynamic model of heat, water and carbon exchange between a vegetated surface and the atmosphere. Details of the model can be found in Anderson et al. [36]. Atmosphere forcing, soil properties and vegetation characteristics are required as inputs of the ALEX model. Forcing data from four different sites are displayed in Figure A1. Criteria for selecting forcing data include that: (1) cloud-free day, (2) daily average incoming solar radiation greater than $200 \mathrm{~W} / \mathrm{m}^{2}$, and (3) relative humidity of air not less than $20 \%$. These criteria are to ensure that the implicit assumption of self-preservation evaporative fraction (EF) during daytime in the daily EF parameterization scheme can be satisfied. The main input quantities required by the ALEX model and the values used in model simulation are listed in Table A1. 
Figure A1. Atmospheric forcing from (a) the Yucheng site in 2010, (b) the Goodwin site in 2006, (c) the Cottonwood site in 2008, and (d) the Audubon site in 2006 ( $R_{\mathrm{g}}$ is the solar incoming radiation; $\mathrm{RH}$ is the relative humidity; $T_{\mathrm{a}}$ is the air temperature; and WS is the wind speed.).
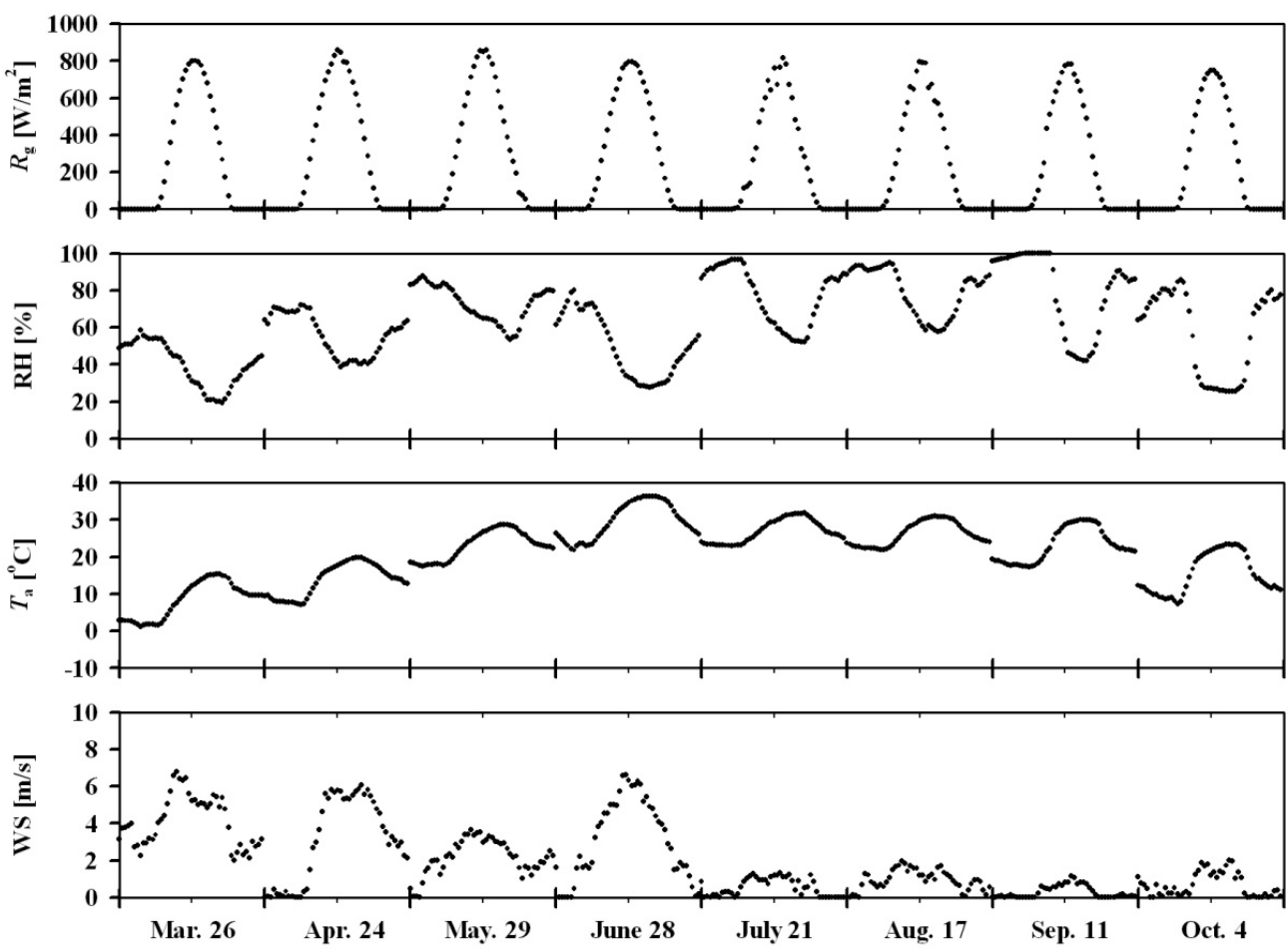

(a) Yucheng (2010)
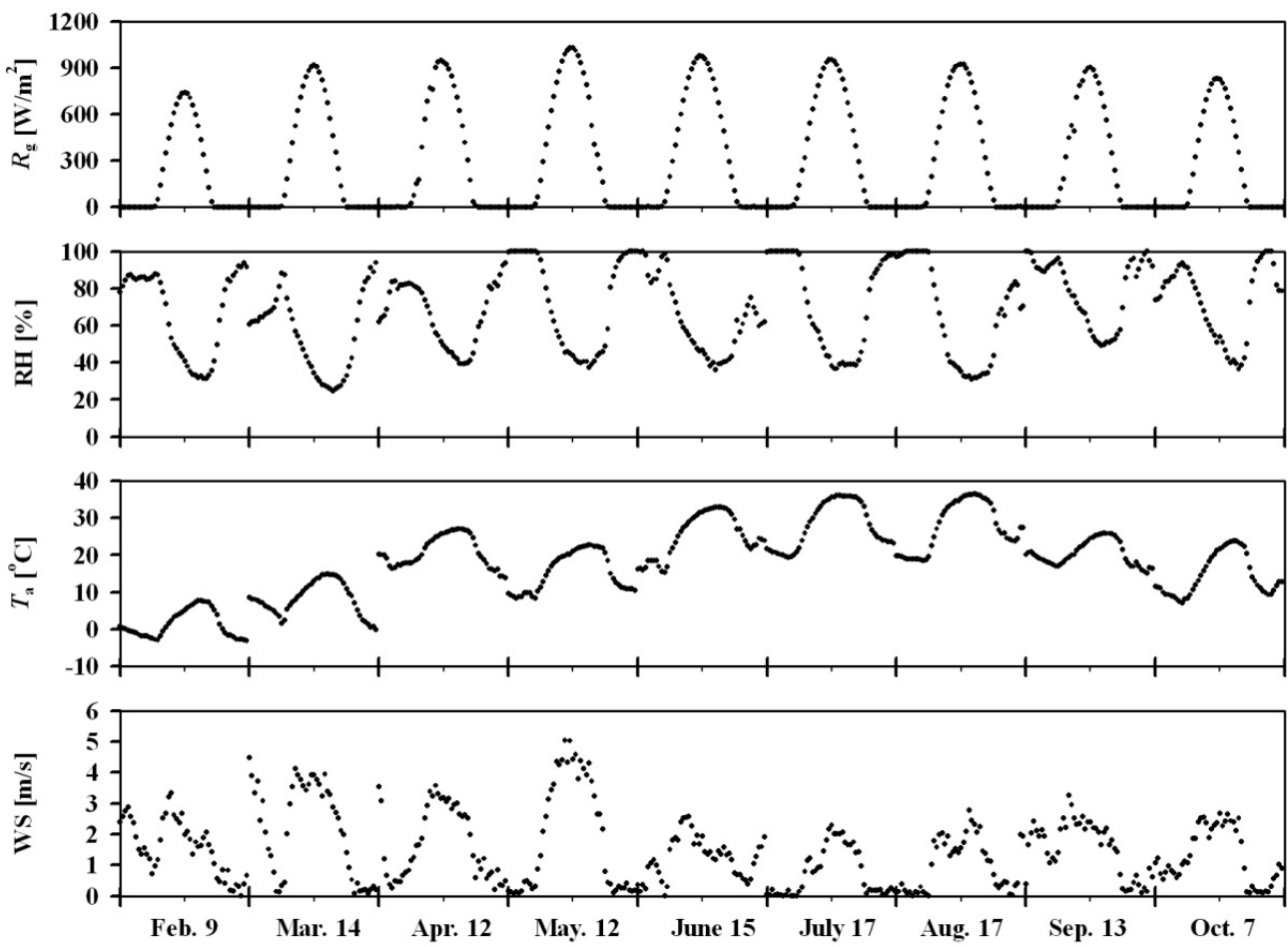

(b) Goodwin (2006) 
Figure A1. Cont.
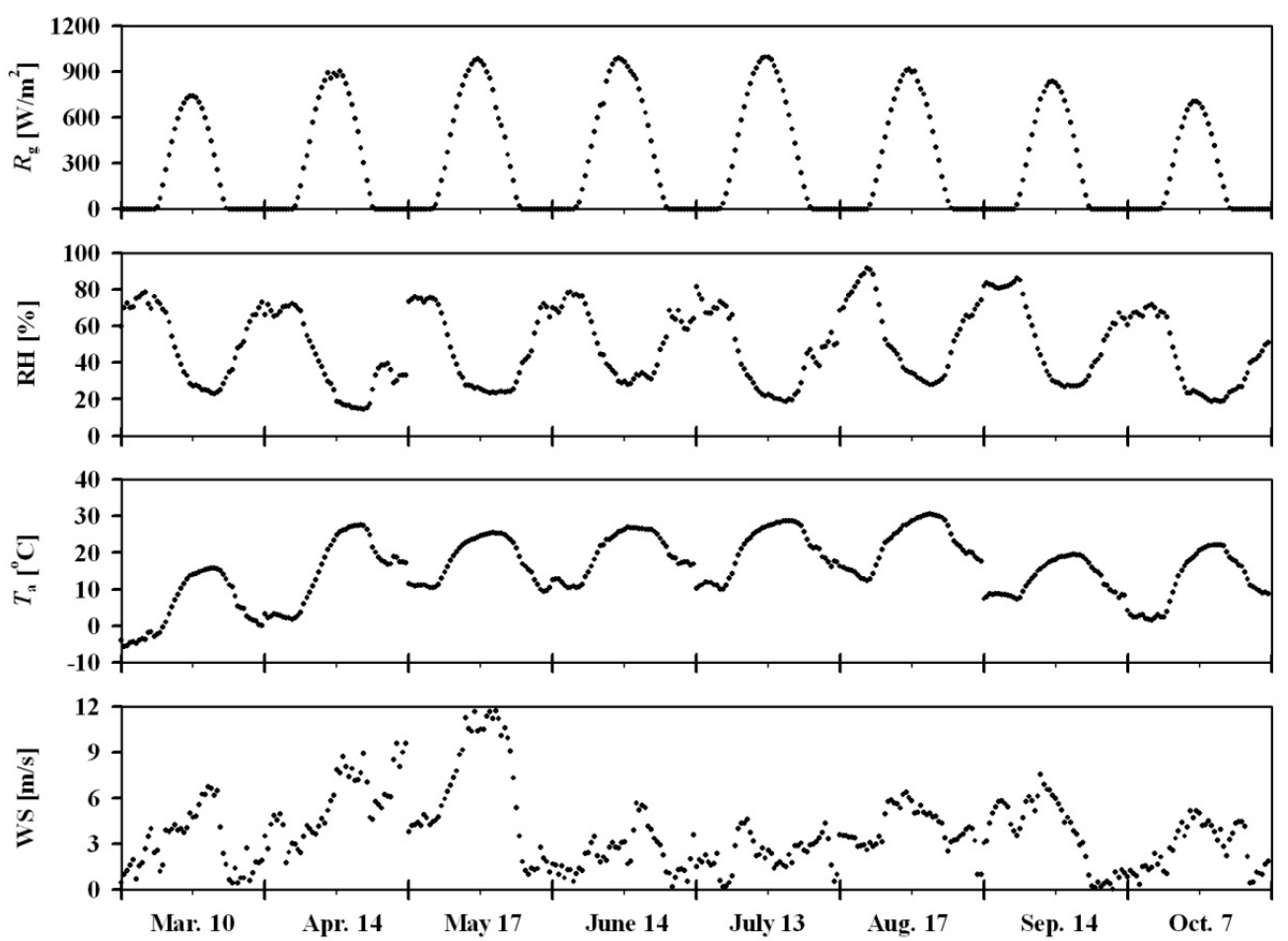

(c) Cottonwood (2008)
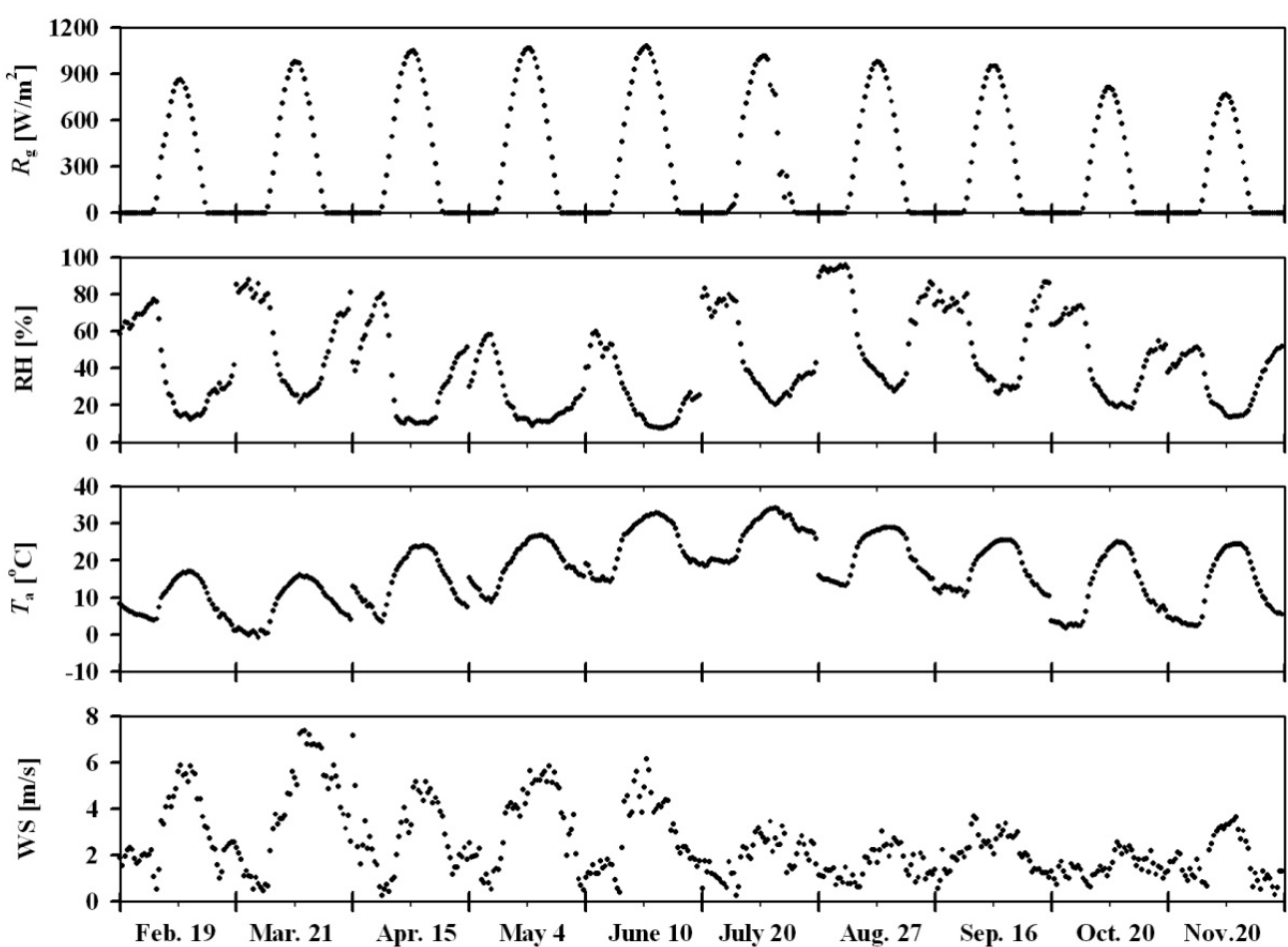

(d) Audubon (2006) 
Table A1. The main input quantities required by the ALEX model and the values used in model simulation for forcing data (a) from the Yucheng site and (b) from three Ameriflux sites.

(a)

\begin{tabular}{|c|c|c|c|}
\hline Quantities & Units & \multicolumn{2}{|c|}{ Values } \\
\hline Site & & \multicolumn{2}{|c|}{ Yucheng } \\
\hline Longitude & & \multicolumn{2}{|c|}{116.5703} \\
\hline Latitude & & \multicolumn{2}{|c|}{36.8291} \\
\hline Year & & \multicolumn{2}{|c|}{2010} \\
\hline Date & & $\begin{array}{l}26 \text { Mar, } 24 \text { Apr, } 29 \text { May, } \\
28 \text { June, } 21 \text { July }\end{array}$ & $\begin{array}{c}17 \text { Aug, } 11 \text { Sep, } \\
4 \text { Oct. }\end{array}$ \\
\hline Measure height & $\mathrm{m}$ & 2.93 & 4.2 \\
\hline Vegetation type & & $\mathrm{C}_{3}$ grass & corn \\
\hline Vegetation height & $\mathrm{m}$ & $0-0.6$ & $0-2.4$ \\
\hline Leaf area index & $\mathrm{m}^{2} / \mathrm{m}^{2}$ & \multicolumn{2}{|c|}{$0-10$} \\
\hline Rooting depth & $\mathrm{m}$ & \multicolumn{2}{|c|}{0.5} \\
\hline Soil texture & & \multicolumn{2}{|c|}{ loam } \\
\hline sand & & \multicolumn{2}{|c|}{0.42} \\
\hline silt & & \multicolumn{2}{|c|}{0.4} \\
\hline clay & & \multicolumn{2}{|c|}{0.18} \\
\hline Bulk density & $\mathrm{g} / \mathrm{cm}^{3}$ & \multicolumn{2}{|c|}{1.5} \\
\hline Moisture release parameter & & \multicolumn{2}{|c|}{4.5} \\
\hline Air entry potential & $\mathrm{J} / \mathrm{kg}$ & \multicolumn{2}{|c|}{-1.1} \\
\hline $\begin{array}{l}\text { Saturated hydraulic } \\
\text { conductivity }\end{array}$ & $\mathrm{K} \cdot \mathrm{g} \cdot \mathrm{s} / \mathrm{m}^{3}$ & \multicolumn{2}{|c|}{$3.7 \times 10^{-4}$} \\
\hline soil water content $(0-2 \mathrm{~m})$ & $\mathrm{m}^{3} / \mathrm{m}^{3}$ & \multicolumn{2}{|c|}{$0.09-0.21,0.43$} \\
\hline
\end{tabular}

(b)

\begin{tabular}{|c|c|c|c|c|}
\hline Quantities & Units & & Values & \\
\hline Site & & Goodwin & Cottonwood & Audubon \\
\hline Longitude & & -89.7735 & -101.8466 & -110.5092 \\
\hline Latitude & & 34.2547 & 43.95 & 31.5907 \\
\hline Year & & 2006 & 2008 & 2006 \\
\hline Date & & $\begin{array}{l}9 \text { Feb, } 14 \text { Mar, } 12 \text { Apr, } 12 \\
\text { May, } 15 \text { June, } 17 \text { July, } \\
17 \text { Aug, } 13 \text { Sep, } 7 \text { Oct }\end{array}$ & $\begin{array}{c}10 \text { Mar, } 14 \text { Apr, } 17 \text { May, } \\
14 \text { June, } 13 \text { July, } \\
17 \text { Aug, } 14 \text { Sep, } 7 \text { Oct }\end{array}$ & $\begin{array}{c}19 \text { Feb, } 21 \text { Mar, } 15 \text { Apr, } 4 \\
\text { May, } 10 \text { June, } 20 \text { July, } \\
27 \text { Aug, } 16 \text { Sep, } 20 \text { Oct, } \\
2 \text { Nov }\end{array}$ \\
\hline Measure height & $\mathrm{m}$ & 4 & 5 & 4 \\
\hline Vegetation type & & $\mathrm{C}_{3}$ grass & soybean & desert $C_{3}$-type shrubs \\
\hline $\begin{array}{c}\text { Vegetation } \\
\text { height }\end{array}$ & $\mathrm{m}$ & $0-1$ & $0-1$ & $0-0.6$ \\
\hline
\end{tabular}


Table A1 (b). Cont.

\begin{tabular}{|c|c|c|c|c|}
\hline Quantities & Units & & Values & \\
\hline Leaf area index & $\mathrm{m}^{2} / \mathrm{m}^{2}$ & $0-10$ & $0-10$ & $0-10$ \\
\hline Rooting depth & $\mathrm{m}$ & 1 & 2 & 0.5 \\
\hline Soil texture & & clay loam & clay loam & silt loam \\
\hline sand & & 0.32 & 0.32 & 0.2 \\
\hline silt & & 0.34 & 0.34 & 0.65 \\
\hline clay & & 0.34 & 0.34 & 0.15 \\
\hline Bulk density & $\mathrm{g} / \mathrm{cm}^{3}$ & 1.5 & 1.5 & 1.5 \\
\hline \multicolumn{5}{|l|}{ Moisture release } \\
\hline parameter & & 5.2 & 5.2 & 4.7 \\
\hline $\begin{array}{l}\text { Air entry } \\
\text { potential }\end{array}$ & $\mathrm{J} / \mathrm{kg}$ & -2.6 & -2.6 & -2.1 \\
\hline $\begin{array}{l}\text { Saturated } \\
\text { hydraulic } \\
\text { conductivity }\end{array}$ & $\mathrm{K} \cdot \mathrm{g} \cdot \mathrm{s} / \mathrm{m}^{3}$ & $6.4 \times 10^{-4}$ & $6.4 \times 10^{-4}$ & $1.9 \times 10^{-4}$ \\
\hline $\begin{array}{l}\text { soil water content } \\
\qquad(0-2 \mathrm{~m})\end{array}$ & $\mathrm{m}^{3} / \mathrm{m}^{3}$ & $0.13-0.25,0.43$ & $0.13-0.25,0.43$ & $0.11-0.23,0.43$ \\
\hline
\end{tabular}

Note: The values of inputs related to the hydraulic properties required by the ALEX model are from Table 9.1 in the book edited by Campbell and Norman [56].

For each atmosphere, five different soil water contents from wilting point to field capacity and the approximate saturated soil water of $0.43 \mathrm{~m} / \mathrm{m}^{3}$ are assigned in ALEX simulation. The leaf area index (LAI) varies from 0 to $10 \mathrm{~m}^{2} / \mathrm{m}^{2}$, which corresponds to fractional vegetation cover $\left(f_{\mathrm{c}}\right)$ from 0 to 1 with an interval of 0.1 . Vegetation height in simulation linearly varies with $f_{\mathrm{c}}$. Because the case of high $f_{\mathrm{c}}$ with wilting soil water rarely occurs in reality, the cases of $f_{\mathrm{c}}$ greater than 0.5 at wilting soil water content were removed. As a result, 61 cases for each atmosphere are finally formed.

(C) 2013 by the authors; licensee MDPI, Basel, Switzerland. This article is an open access article distributed under the terms and conditions of the Creative Commons Attribution license (http://creativecommons.org/licenses/by/3.0/). 